\title{
GENERAL EDUCATION VS. VOCATIONAL TRAINING: EVIDENCE FROM AN ECONOMY IN TRANSITION
}

\author{
Ofer Malamud \\ Cristian Pop-Eleches \\ Working Paper 14155 \\ http://www.nber.org/papers/w14155
NATIONAL BUREAU OF ECONOMIC RESEARCH
1050 Massachusetts Avenue
Cambridge, MA 02138 \\ July 2008
}

We wish to thank Daron Acemoglu, Kerwin Charles, Claudia Goldin, Caroline Hoxby, Larry Katz, Marcos Rangel, three anonymous referees, and seminar participants at Columbia, Chicago, Essex, Tel-Aviv, IUPUI, LSE, Michigan, NBER Education Program Meetings, NEUDC, and Yale. Ofer Malamud gratefully acknowledges the financial support of the Spencer Foundation. All errors are our own. The views expressed herein are those of the author(s) and do not necessarily reflect the views of the National Bureau of Economic Research.

NBER working papers are circulated for discussion and comment purposes. They have not been peerreviewed or been subject to the review by the NBER Board of Directors that accompanies official NBER publications.

(C) 2008 by Ofer Malamud and Cristian Pop-Eleches. All rights reserved. Short sections of text, not to exceed two paragraphs, may be quoted without explicit permission provided that full credit, including (C) notice, is given to the source. 
General Education vs. Vocational Training: Evidence from an Economy in Transition

Ofer Malamud and Cristian Pop-Eleches

NBER Working Paper No. 14155

July 2008

JEL No. I21,J24,P20

\begin{abstract}
$\underline{\text { ABSTRACT }}$
This paper examines the relative benefits of general education and vocational training in Romania, a country which experienced major technological and institutional change during its transition from Communism to a market economy. To avoid the bias caused by non-random selection, we exploit a 1973 educational reform that shifted a large proportion of students from vocational training to general education while keeping average years of schooling unchanged. Using data from the 1992 and 2002 Romanian Censuses and household surveys from 1995-2000, we analyze the effect of this policy with a regression discontinuity design. We find that men in cohorts affected by the policy were significantly less likely to work in manual or craft-related occupations than their counterparts who were unaffected by the policy. However, in contrast to cross-sectional findings, we find no difference in labor market participation or earnings between cohorts affected and unaffected by the policy. We therefore conclude that differences in labor market returns between graduates of vocational and general schools are largely driven by selection.
\end{abstract}

Ofer Malamud

Harris School of Public Policy Studies

University of Chicago

1155 East 60th Street

Chicago, IL 60637

and NBER

malamud@uchicago.edu

Cristian Pop-Eleches

Columbia University

1022 International Affairs Building, MC 3308

420 West 118th Street

New York, NY 10027

and NBER

cp2124@ columbia.edu 


\section{Introduction}

Vocational training was an integral part of the educational system in the planned economies of Central and Eastern Europe. ${ }^{1}$ However, with the fall of Communism and subsequent transition to market economies, many of the centralized sectors which relied heavily on vocational and technical training suffered a major decline. Like other countries undergoing this transition, Romania experienced substantial technological and institutional change as economic activities gradually reoriented towards new sectors. The success of such a profound economic transformation depended on having people adjust to new circumstances. ${ }^{2}$ Were individuals with vocational training less able to adapt to these changes? An OECD (2000a) report on Romania argues that some of the blame for its disappointing economic performance during the transition period rests with the inflexibility of vocational training: "Under an emerging democratic and competitive market system, the state enterprises have had to adapt to changing demand and new competition. This adaptation has been hindered by a workforce trained in narrow specializations with little ability to adjust to changing skill demand." (p. 109) Using a regression discontinuity design, this paper examines whether individuals with general education had more success in Romania's transitory labor market than their counterparts who received vocational training.

Most of the empirical evidence on the benefits of vocational and general education during transition is based on cross-sectional studies. In Romania, Earle (1997) finds that individuals with a general education were more likely to find jobs in the service sector and less likely to end up in agriculture or out of the labor force than those with vocational training. Similar

\footnotetext{
${ }^{1}$ UNESCO statistical yearbooks $(1969,1975,1981)$ indicate that a majority of full-time students in Eastern Europe were enrolled in vocational and technical programs under Communism from 1950 to 1980. This represented a substantially higher fraction of vocational training than in any other region of the world.

${ }^{2}$ Barberis, Boycko, Shleifer and Tsukanova (1996) provide evidence on the important role of new human capital for restructuring during the transition and Brainerd (1998) shows that young educated men were able to take advantage of the new profit making opportunities in Russia's early transition.
} 
findings emerge from other countries during their transition from Communism to a marketbased economy. ${ }^{3}$ (Nesporova, 2001) However, interpreting these results is difficult because selection into different types of educational tracks is not random. Admission into general and vocational schools is usually determined by a competitive examination so less able students are more likely to enroll in vocational programs. This is certainly the case for Romania. Even in countries such as England and the United States which do not administer competitive examinations, there is a large degree of self-selection out of vocational courses. Reviewing the literature on general education and vocational training, Bennel (1996) finds selection bias to be "a pervasive weakness of almost all the... studies." ${ }^{4}$ (p. 238) We address the problem of selection bias by analyzing a unique educational reform in Romania which shifted a large proportion of students from vocational training to general education.

We also contribute to a broader debate on the trade-offs between general and vocational education, often framed by the contrast between the American and European systems of education. ${ }^{5}$ Whereas the United States emphasizes formal general education in secondary schools, much of Europe relies on vocational training and apprenticeships to prepare its workforce for the labor market. Goldin (2001, p. 277) notes the essential trade-off between these different approaches: "Formal, school based education enabled American youths to change occupations over their lifetimes and to respond rapidly to technological change. Apprenticeships and highly specific training were more cost effective for individuals who

\footnotetext{
${ }^{3}$ A notable exception is Munich, Svejnar, and Terrell (2005) who do not find significantly different returns to vocational and general secondary education using rich data from the Czech republic. Indeed, they find that privatized and de novo private firms actually pay a significant premium for vocational secondary education.

${ }^{4}$ Lechner (2000) attempts to address this issue using propensity score methods and finds no evidence of any positive effects on employment probabilities and earnings from a public sector vocational training programs in East Germany.

${ }^{5}$ The difference between (firm) specific and general skills also plays an important role in the standard theory of human capital. Becker (1964) shows that, in a competitive labor market, employers pay for training that is firm specific while workers pay for investments in general skills. However, Acemoglu and Pischke (1998) demonstrate that, in models with non-competitive labor markets, firms will invest even in the general skills of their workers.
} 
expected to spend their lives in the same place and in the same industry and occupation." 6 Krueger and Kumar (2004a, 2004b) have recently applied this logic to explain the trends in relative growth between the US and Europe over the previous half-century. Nevertheless, as Acemoglu and Pischke (1999) explain, more empirical research is needed to understand the optimal mix between general schooling and vocational training. We explore these issues in the context of a transition economy, where workers who were provided with vocational training under central planning may have found it more difficult to adapt to the flexible environment generated by rapid technological change.

In this paper, we exploit a 1973 educational reform in Romania which prevented students from entering vocational schools after only 8 years of schooling and, instead, required them to receive an additional two years of general education. As a result of this policy change, secondary school cohorts born after January 1, 1959 were treated with more general education and less vocational training than cohorts born immediately before this date. We take advantage of detailed information on date of birth to estimate a reduced-form effect of the policy using a regression discontinuity design. Empirical evidence indicates that average years of schooling across these cohorts did not change as a result of the educational reform. ${ }^{7}$ Hence, we can identify an unbiased estimate for the effect of the policy on labor market outcomes and, with some additional assumptions, derive the effect of a year of vocational versus general education.

Data from the Romanian Censuses of 1992 and 2002 and household surveys from 19952000 enables us to examine labor market returns throughout the transition period. Although most of our results also hold for women, we focus our analysis on men since they were the

\footnotetext{
${ }^{6}$ That technological change may affect the return to general education is closely related to early work by Nelson and Phelps (1966) who argue for higher returns to education in the presence of more rapid technological change.

${ }^{7}$ This contrasts with other educational reforms in Europe which served to increase average years of schooling. For example, Meghir and Palme (2005) show that a Swedish reform which abolished selection into academic and non-academic streams also led to large increases in years of schooling.
} 
ones most affected by the policy change. We find that men in cohorts born immediately before and after January 1, 1959 received very different types of secondary education and consequently experienced quite different occupational outcomes, but had very similar levels of labor market participation and earnings between 1992 and 2002. Among men employed in 1992, those in cohorts affected by the policy were significantly less likely to be employed as manual workers and craftsmen, confirming that the policy did not simply relabel schools but actually led to changes in occupational composition. However, the incidence of unemployment and nonemployment is not significantly different between cohorts affected and unaffected by the educational reform, even in the later stages of the transition period when general education may have been more valuable. Differences in family income and wages from the period 1995-2000 are also insignificant between these cohorts. These findings are in sharp contrast to cross-sectional results where general education is associated with significantly better labor market outcomes than vocational training. While the drastic short-term expansion in general education may have introduced some crowding resource constraints, we show that this factor is unlikely to explain why men who received more general education due to the 1973 educational reforms do not perform better. Hence, we interpret these results as evidence that the large cross sectional differences in labor market outcomes between graduates of vocational and general secondary schools are driven mainly by selection.

The paper is organized as follows. Section 2 provides a background of the Romanian educational system and the 1973 educational reform as well as the Romanian labor market during the transition period. Section 3 describes the data and the relevant samples. Section 4 explains the empirical strategy used to identify the reduced-form effect of the policy and derive the effect associated with a year of general education versus vocational training. Section 5 presents the results, and Section 6 concludes. 


\section{Background}

\subsection{The Structure of Education in Romania}

Apart from the changes induced by the 1973 reform, the structure of education in Romania throughout the 1970s was relatively stable. Students generally began compulsory schooling by entering schools of general education (scoală de cultură generală ) after the age of 6 . More specifically, students entered grade 1 in September of the year following the calendar year in which they reached 6 years of age. Since the mid-1950's, these schools offered a continuous sequence of 8 years of general education, nominally composed of primary education from grades 1 to 4 and gymnasium education from grades 5 to 8 . After graduating from schools of general education, students could continue into secondary school lyceums or enter vocational schools and apprenticeship programs.

Lyceums operated at two distinct levels. The first level corresponded to grades 9 and 10 of compulsory general education, while the second level encompassed general education in grades 11 and $12 .{ }^{8}$ Admission to the first and second level was determined by a competitive entrance exam. Graduates from the first level of lyceum who did not take further courses in the second level received a certificate of graduation from 10-year compulsory education (cerificat de absolvire a învătămîntului obligatoriu de 10 ani). They could also apply to enter an upper-level track in vocational schools. Graduates from the second level received a certificate of graduation (certificat de absolvire) or a baccalaureate diploma (diploma de bacalaureat). Curriculum in lyceums was relatively homogenous despite some differences in emphasis and specialty:

"During the first 2-years of lyceum education, students are offered a basically uniform curriculum both in academic and practical subjects whatever the character or orientation of a lyceum, its stated aims are to offer a well-balanced integrated curriculum

\footnotetext{
${ }^{8}$ At the second level, there was some specialization across lyceums. Among the different types of lycuems were industrial, math and science, economic, and agricultural lyceums.
} 
composed of a number of subjects in the humanities, social studies, and the sciences, as well as subjects related to practical training in a particular field." (Braham, 1978, p. 10)

According to a curriculum handbook from the early 1970s, "technical practical" training accounted for 20.2 percent of the total hours of the curriculum in general secondary lyceums. (Blideanu, 1972, p. 122). In other words, approximately 80 percent of the curriculum in lyceums was devoted to general education. ${ }^{9}$

Vocational schools (şcoli profesionale) provided training in numerous trades ranging from aircraft maintenance to winemaking. They also operated at two levels: a lower vocational track for students who had completed 8 years of general education and an upper vocational track for students who had received an additional two years of general education in the first level of lyceum. Official guidelines regarding the organization and functioning of vocational education stated that "the proportion of practical training will be $70-80 \%$ of the total number of hours" in vocational schools. (Official Bulletin Nr. 67, 1977) The length of training varied by trade and depended on whether students completed an additional two years of general education: "In 1967-68 vocational schools offered training in 232 trades, 175 of which required 3 years and 57, 2 years. With the decision to extend the compulsory educational system to 10 years the duration of day sessions in vocational schools was reduced in most fields." (Braham, 1972, p. 73) Indeed, for graduates from the first stage of lyceum schools, training usually lasted only 1 year. (Dimitriu et. al, 1981, p. 41) On-the-job apprenticeships (ucenicia la locul de munc $\breve{a}$ ) trained workers in largely the same fields as those offered by vocational schools. The practical training period for apprenticeships was also normally 3 years. Thus, although on-the-job apprenticeships were generally provided on-site rather than in vocational schools, they were sufficiently similar to be considered jointly in most government statistics.

\footnotetext{
${ }^{9}$ These approximate proportions have been confirmed in numerous conversations with school administrators in Romania who had first-hand experience of the 1973 educational reform.
} 
We shall do the same in our analysis.

Several different institutions provided further education beyond vocational and general schools. Technical schools for master craftsmen admitted graduates of vocational schools and lyceums who had spent between 3 and 5 years in production. Postsecondary specialization schools admitted graduates of lyceums and trained them in specialized fields ranging from aircraft construction to radiology. Finally, entrance to higher education in universities was open only to graduates of the second level of lyceum schools and required a baccalaureate diploma.

\subsection{The Educational Reform of $\mathbf{1 9 7 3}$}

The educational reform of 1973 prevented students from pursuing vocational training after only 8 years of general education and, instead, required them to complete two additional years of general education. The educational reforms of 1973 were actually preceded by Law No. 11 of May 1968, which called for the extension of compulsory general schooling from 8 to 10 years. However, five years after establishing government commitment for extending compulsory general schooling, "the rate of 10-year school generalization was thought to be inadequate." (Dimitriu et. al, 1981, p. 37) As a result, the government introduced an explicit mandate to implement the 10 year system of general education under the provisions of Decree No. 278 and the Resolution of the Communist Party's Central Committee of June 18 and 19, 1973. In fact, this policy did not alter total years of schooling but, rather, substituted more general education in lieu of vocational training. The Resolution of June 1973 stated that "beginning with the school year 1974-75, the entire graduating class of grade 8 will start in

grade 9 of lyceums; vocational schools will no longer accept students from this class [grade 
8] directly." ${ }^{10}$ We also provide evidence to show that the average years of schooling remained essentially unchanged after these educational reforms. The structures of the educational system before and after the change in 1973 are depicted in Figure 1. Following the reform, students who would have otherwise received about three years of vocational training were required to obtain an additional two years of general education. ${ }^{11}$

Depending on their aptitudes, skills, and preferences, graduates of the first level of lyceum schools could (i) enter the workforce, (ii) continue to vocational school for 1 year, or (iii) continue to grades 11 and 12 in the second level of lyceum schools. Though the policy affected students in different ways, there was no change in overall educational attainment. However, the emphasis on additional general education after 1973 caused a marked decrease in the prevalence of vocational training. As one secondary source explains, "the number of apprentices decreased during the 1970's because of the extension of compulsory education to include 2 years in the lyceum," and similar drops were observed in the number of students in vocational schools. (Braham, 1978, p. 11) But even students who continued to vocational schools after completing the 1st stage of lyceum were treated with more general and less vocational training following the policy change.

The Resolution of June 1973 also introduced measures to assure that sufficient qualified teachers and school resources (such as science laboratories, classrooms, and dormitories) were allocated to local authorities. In most cases, these measures did not require any physical movement of resources; teachers and schools remained the same but their training and the curriculum were changed. As stated in the 1973 Resolution:

"In order to provide for an effective educational environment and to use the existing

\footnotetext{
${ }^{10}$ These excerpts from the Resolution of the Communist Party's Central Committee of June 18 and 19 , 1973 are translated by the authors from the original Romanian text.

${ }^{11}$ Decision No. 577 of the Council of Ministers in 1975 reaffirmed the earlier resolutions concerning 10 year compulsory general education and the restrictions on entry into vocational schools. Finally, all of these changes were brought together under Law No. 28 of May 1978, which replaced the earlier Law No. 11 of May 1968.
} 
facilities efficiently,...lyceums will, in general, function within the same premises as vocational schools and under the same leadership."

We can document some of these changes using the Annual Statistics of the Socialist Republic of Romanian. Appendix Figure 1 shows the large decline in the number of students enrolled in vocational schools and on-the-job apprenticeships between the school years 1973-74 and 1975-76. These declines occurred across all specialities in vocational schools. During this period, enrollment in lyceums increased sharply, as shown in Appendix Figure 2. Moreover, the number of teachers in vocational schools fell while the number of teachers in lyceums rose in the initial years following the educational reform.

Further evidence for these dramatic changes is available from the Romanian Census. Since students began compulsory schooling at age 6 , they would have completed grade 8 by age 14 and grade 10 by age 16 . Consequently, students born in 1958 would have been unaffected by the policy while those students born in 1959 would have been required to continue to grades 9 and 10 of lyceum schools. Figure 2 shows the highest educational attainment for all men by year of birth. There is a sharp decline in the proportion of men with vocational training between cohorts born in 1958 and 1959. At the same time, we observe a sharp increase in the proportion of men who completed a general lyceum education. No such discontinuity is observed for the proportion completing only lower/primary or higher education. Thus, the 1973 educational reform altered the proportion of students across vocational and general education as well as the nature of their exposure to vocational training.

\subsection{The Labor Market in Transition}

Compared to other countries in Central Europe, such as Poland, Hungary, and the Czech Republic, Romania's transition to a market economy has been relatively more difficult. This has been attributed to the unfavorable initial conditions resulting from Ceausescu's economic, so- 
cial and political policies and the overly cautious approach towards market-oriented reforms by Romania's political leadership. (OECD, 2000b) Romania's macroeconomic performance in the early 1990's began with a large decline in GDP and increasing inflation. Although it experienced some positive economic growth in the mid-1990s, Romania suffered another macroeconomic crisis in late 1996 due to the slow pace of restructuring within state owned enterprises. As a result, a newly elected center-right coalition embarked on an IMF supported macroeconomic stabilization and structural reform program in 1997. These reforms eliminated all remaining price controls, tightened fiscal policies, and accelerated the rate of privatization. This led to mass layoffs in state firms as well as decreases in real wages and a contraction in real GDP. Nevertheless, from 2000 onwards, Romania has experienced a sustained recovery.

The gradual development of a new private sector and the privatization and restructuring of state-owned enterprise had a major impact on the labor market. Registered unemployment rose from essentially no unemployment in 1990 to over 10 percent in 1993. (Earle and Pauna, 1996, 1998) Industrial employment fell from almost 45 percent of total employment in 1989 to about 30 percent in 1995. Appendix Figure 3 plots the unemployment rate during the transition period and also shows the sharp increase in unemployment after the onset of the structural reforms in early 1997. The large decrease in industrial employment was partly offset by a large increase in agricultural employment during this period. Following land reforms in 1991, many workers who lost their jobs in the cities migrated back to the countryside and started to be active in low-productivity subsistence farming. Empirical evidence indicates that very young and old workers were more likely to lose their jobs and less likely to find new employment opportunities. (Voicu, 2002) Moreover, individuals with vocational training had worse labor market outcomes than those with general education. As mentioned earlier, Earle (1997) finds that individuals with a general education were more 
likely to find jobs in the service sector and less likely to end up in agriculture or out of the labor force than their counterparts with vocational training.

Romania also made a number of legislative changes with respect to the functioning of the labor market. Unemployment benefits were introduced in 1991 and covered about 50\% of previous wages in the first nine months followed by a reduced allowance for another 18 months. As part of its reform efforts in 1997, the government also introduced a system of severance benefits to eligible workers who chose to leave specific state enterprises. (OECD, 2000b) Thus, by the end of the transition period, the basic legislation governing employment conditions and termination of job contracts was considered relatively liberal by international standards. (OECD, 2000b)

\section{Data}

We use three different data sources for our research. The first is a sample from the 1992 Romanian Census which provides information on occupational structure and labor market outcomes relatively early in the transition process. ${ }^{12}$ The second is a sample from the 2002 Romanian Census which provides a snapshot of these same outcomes towards the end of the transition period. These two census datasets also provide sufficient power to employ a regression discontinuity design and estimate fairly precise labor market outcomes. Finally, we pool six annual LSMS-type household surveys from 1995-2000 which are based on yearly cross-sectional representative samples. ${ }^{13}$ While the LSMS houeshold data is based on smaller samples, it has the advantage of providing additional information on wages and income.

\footnotetext{
${ }^{12}$ This sample combines two independent random samples from the 1992 Romanian Census: a 15\% sample provided by the Population Activities Unit (PAU) of the United Nations Economic Commission for Europe (UNECE) and a 10\% sample recently released by IPUMS International. We have verified that these two samples are two separate random draws from the universe of all responses.

${ }^{13}$ These surveys were conducted by the National Statistics Commission of the Romanian Ministry of Labour and Social Protection and followed the exact format of the World Bank's Living Standards Measurement Studies (LSMS) for Romania in 1994.
} 
Moreover, the timing of these survey rounds allows us to take a closer look at labor market dynamics before and after the structural reforms of 1997 .

All three data sources provide information on the month and year of birth which proves essential in identifying the discontinuity induced by the policy within a narrow window of time. They also distinguish between various levels of education attainment: completion of primary education, gymnasium education, first stage of lyceum education (grade 9 and 10), second stage of lyceum education (grades 11 and 12), vocational training and apprenticeships, post-secondary technical education, and higher education. However, these categories are mutually exclusive so we cannot determine whether students with vocational training and apprenticeships also completed the first stage of lyceum education (for cohorts unaffected by the educational reform). Since this makes it more difficult to estimate the local average treatment effect of vocational training, we use aggregate data on school enrollment from the Annual Statistics of the Socialist Republic of Romanian to calculate the effect of the policy on the treated population and the local average treatment effect of vocational training. In addition, these three data sources include background variables such as ethnicity and region of birth, as well as indicators for urban/rural place of birth in the census data. ${ }^{14}$

The census data contain several outcome variables of interest pertaining to labor market participation and earnings. We focus on two different measures of labor market participation: unemployment and non-employment. The former is restricted to individuals that are actively seeking work and therefore part of the labor force. The latter consists of all individuals not currently working and includes those out of the labor force. ${ }^{15}$ We have detailed information on current and previous occupations based on 3 digit International Standard Classification

\footnotetext{
${ }^{14}$ Other socio-economic indicators, such as information on the status of the dwelling and availability of amenities, are available. However, since these are contemporaneous with other outcomes, they are probably not valid proxy controls for income and class.

${ }^{15}$ Note that the reference period for the question on employment status changed from the "moment of the census" in the 1992 Census to "the previous week" in the 2002 Census and the 1995-2000 LSMS.
} 
of Occupation (ISCO) 88 codes. We use this information to infer whether individuals are employed in a manual (ISCO codes 5-9) or craft-related occupation (ISCO code 7). The 1995-2000 household surveys contain similar questions related to unemployment and nonemployment but somewhat less detailed information on occupations. However, they contain information on individual wages and family income which are not available in the census data.

Table 1 presents summary statistics for all the datasets described above. These are shown for the full sample of men born 3 years before and after the policy change, as well as a restricted sample of men who completed vocational or general schools in these same cohorts. For the most part, we will restrict our attention to this latter sample of men whose highest level of educational attainment is secondary schooling. Figure 2 shows that the policy did not alter the proportion of students between secondary education and the higher or lower levels of education. Students completing their education after primary school or gymnasium were mostly living in relatively rural areas that could not extend their network of lyceums while students completing higher education should not have been affected by the policy. ${ }^{16}$ The next section confirms this in a regression discontinuity setting. Consequently, we focus on men who received a secondary level education and estimate the effect of the policy for sample of the entire population only as a robustness check.

\footnotetext{
${ }^{16}$ In fact, the government established explicit rules about the provision of schools. If the number of students registered in grade 9 exceeded 25, the community had to operate a 10-year school of general education; if the number of students registered in grade 5 is at least 25 , the community had to operate a 8-year school of general education; and if the number of children aged 6-9 was at least 7, the community had to operate a 4-year school.
} 


\section{Empirical Strategy}

\subsection{A regression discontinuity design}

Most empirical studies examining the effect of vocational training adopt a simple specification in which individuals who receive vocational training are distinguished from those who receive a general education: ${ }^{17}$

$$
\text { outcome }_{i}=\beta^{\prime} \mathbf{X}_{i}+v V O C_{i}+\varepsilon_{i}
$$

where outcome $_{i}$ is a labor market outcome such as unemployment or wages, $V O C_{i}$ is equal to 1 if individual $i$ received vocational training and 0 otherwise, and $\mathbf{X}_{i}$ is a set of observable characteristics for individual $i$. According to this specification, the coefficient on $\operatorname{VOC}_{i}$ represents the difference between the benefit from vocational training and general education (in terms of some labor market outcome). ${ }^{18}$ However, vocational training is usually correlated with unobserved ability because selection into different tracks is based on a competitive examination or because individuals with higher ability choose to enter general rather than vocational schools.

We address the possibility of omitted variable bias using the 1973 educational reform which prevented students from entering vocational schools with only 8 years of schooling and, instead, required them to receive an additional two years of general education. Since this reform took effect during the 1974-75 school year and students entered grade 1 in September after the calendar year in which they reached 6 years of age, those born before January 1 , 1959 were unaffected by the policy while those born after this date were treated with more general education and less vocational training. With detailed information on date of birth,

\footnotetext{
${ }^{17}$ For example, see the early work on vocational training by Grasso and Shea (1979) and Meyer (1982). Neuman and Ziderman $(1991,1999)$ introduce some extensions to this simple model.

${ }^{18}$ Clearly, an accurate cost-benefit analysis would require consideration of the relative costs in providing vocational and general education. We abstract from this here but evidence from other studies suggests that vocational training is often more expensive than general education (Bennel, 1996).
} 
we can estimate a reduced-form effect of the policy using a regression discontinuity design:

$$
\text { outcome }_{i}=\beta^{\prime} \mathbf{X}_{i}+\delta A F T E R_{i}+f\left(c_{i}\right)+\varepsilon_{i}
$$

where $A F T E R_{i}$ is equal to 1 if individual $i$ was born on or after January 1, 1959 and 0 if born on or before December 31,1958 , and $f\left(c_{i}\right)$ is a function of the date of birth, which is the forcing variable in this context. The coefficient on $A F T E R$ represents the reduced form effect of the 1973 educational reform. As in many recent studies employing this technique, we specify a flexible parametric model by including higher order polynomials of date of birth which are allowed to vary on either side of the discontinuity. ${ }^{19}$ Our primary specification uses a cubic trend in month of birth fully interacted with AFTER (i.e. a cubic spline) but we also estimate regressions with alternative polynomial functions for robustness. Binary outcome variables are estimated with a linear probability model. Estimating this equation using non-parametric methods, along the lines of Hahn, Todd, and van der Klaauw (2001) and Porter (2003), also leads to similar results.

The main set of observable characteristics, $\mathbf{X}_{i}$, includes ethnicity, region of birth, and an indicator for urban or rural place of birth. ${ }^{20}$ In practice, these control variables have very little effect on our estimates of the discontinuity and serve mainly to increase precision. However, we also include dummy variables for calender month of birth to control for any seasonal differences between individuals born in different months. ${ }^{21}$ Restricting attention to a narrow window of cohorts minimizes any confounding effects associated with age or time

\footnotetext{
${ }^{19}$ See Dinardo and Lee (2004) for use of parametric functions in regression discontinuity design. Lee and McCrary (2005) and Card, Dobkin, and Maestas (2004) specifically use parametric functions of date of birth.

${ }^{20}$ As mentioned previously, indicators for urban/rural place of birth are only available in the census data. Furthermore, all regressions using the pooled LSMS household data include fixed effects for survey year.

${ }^{21}$ Note that compulsory schooling in Romania is based on years attended rather than age so there is no concern about differences in years of schooling between those born on either side of the school entry cutoff. But any such differences would be eliminated by the calendar of month dummies, in any case.
} 
of entry into the labor force. But an excessively narrow window reduces the sample size and leads to imprecise estimates. We therefore focus on a window that includes cohorts born 3 years on either side of the cutoff - so that month of birth ranges from -36 to 35 , with 0 representing the first cohort affected by the policy. However, we also show results using several alternative windows for robustness. All regressions cluster on month of birth in order to avoid the problems associated with specification error in the case of discrete covariates (Lee and Card, 2007).

\subsection{Effect of the reform on educational outcomes}

Estimating equation 2 with educational outcomes, Panel A of Table 2 demonstrates the dramatic change in the probability of completing vocational school for cohorts affected by the policy. Column (1) indicates that the probability of completing vocational school declined by .08 among the entire male population. In other words, the probability of completing vocational school fell by about .13, or more than 20 percent, among men with secondary education. Column (2) shows a corresponding increase in the probability of completing general lyceum school while column (3) confirms that the proportion of men who completed any type of secondary school did not change with the introduction of the policy. The effect of the 1973 educational reform is even more striking in graphical form. Panels A and C of Figure 3 plot the proportion of secondary educated men with vocational training by month and week of birth. Each panel indicates an extremely sharp discontinuity after January, 1959 - normalized as month or week 0. Men born merely two weeks apart were exposed to extremely different types of education. In contrast, panels B and D of Figure 3 reveal no change in the proportion of secondary educated men out of the entire population before and after the policy change.

The evidence described above indicates the change in the proportion of students who 
completed any type of vocational school as a result of the 1973 educational reform. Since we only observe the highest level of education attained, we cannot discern the effect on students who were affected by the policy and continued onto the upper vocational track after receiving an additional two years of general education. But these students would also have been treated with less vocational training and more general education. Consequently, in order to properly interpret the effect of the policy, we need to account for the effect on the entire treated population. The next section describes how we translate the reduced-form effect of the policy into the effect of the policy on the treated population and the local average treatment effect of a year of vocational training.

\subsection{Interpreting estimates}

If we could identify the group of students who entered vocational school directly after grade 8 prior to the educational reform, we could estimate the effect of the policy on the treated population directly using two-stage least squares (2SLS). Unfortunately, we only have information on the highest level of education attained so we cannot distinguish vocational students in the lower track who were affected by the policy from vocational students in the upper track that were not affected by the policy. Instead, we use supplementary enrollment data from the Annual Statistics of the Socialist Republic of Romanian to calculate the proportion of students who entered vocational school after grade 8 prior to the educational reform and scale up the reduced-form effect of the policy to calculate the effect on the treated population. ${ }^{22}$ As explained in Appendix A, we determine that approximately 50 percent of students with vocational training were in the lower vocational track. Hence, we conclude

\footnotetext{
${ }^{22}$ This resembles the standard calculation used in moving from an intention-to-treat (ITT) estimator to a treatment-on-the-treated (TOT) estimator. However, the reason for employing this method here is that we cannot identify the group of students who were affected by the treatment, rather than the conventional worry that individuals may be self-selecting into the treatment.
} 
that about 33 percent of students with secondary education were affected by the policy. This implies that we need to scale up the reduced-form estimate by a factor of 3 to derive an estimate for the effect of the policy on the treated population.

The effect of the policy on the treated population is still somewhat difficult to interpret because the policy did not affect exposure to vocational training in the same way for all individuals. Appendix A uses both census and aggregate enrollment data to provide a rough calculation of the average difference in vocational training before and after the policy change. These estimates suggest that, among individuals whose highest educational attainment was secondary schooling, the average decrease in vocational training was 0.8 years. Now, rather than scaling the reduced-form estimate of the effect of the policy by the proportion of individuals who were affected by the policy, we can scale the reduced-form estimate by the average change in years of vocational training induced by the policy. In other words, we calculate the local average treatment effect (LATE) of a year of vocational versus general education. ${ }^{23}$ Undertaking this calculation, we conclude that the effect of an additional year of vocational training instead of general education on labor market outcomes is approximately $1.25 \delta$.

\subsection{Testing for selection}

Since higher ability students tended to be selected into general secondary schools by competitive examination, students affected by the policy were probably lower on the ability distribution than those who attended general lyceums before the educational reform. Hence, we expect the average ability of students receiving general education to decline after the policy change. But unfortunately, we do not have good measures of ability in our data. Instead, we examine whether students were born in an urban or rural area which serves as a

\footnotetext{
${ }^{23}$ Since we are estimating a local average treatment effect (LATE) for individuals affected by the policy, these results may not hold for the population at large. See Imbens and Angrist (1994) for a thorough discussion of this issue and some instructive examples.
} 
proxy for socioeconomic background and is correlated with higher educational attainment. Panel B of Table 2 shows the likelihood of being born in an urban area for samples of men with different levels of educational attainment. Specifically, column (2) reveals that men who received general education after the policy change were 6 percentage points less likely to have been born in an urban area than general-educated men who were unaffected by the policy. ${ }^{24}$ This result supports our contention that more able or more advantaged students were selected into general secondary schools. Column (3) in Panel B of Table 2 also shows that the proportion of men with secondary education who were born in urban regions did not change after the educational reform. We have also confirmed that indicators for ethnicity and region of birth did not exhibit any discontinuous change around the discontinuity. This is reassuring evidence that the composition of men who completed secondary level education did not change after the policy reform and serves as a check for the validity of the regression discontinuity design.

\subsection{Quantity of schooling}

We have information on years of schooling for a subsample of individuals in the LSMS household surveys of 1995 and 1996. Using this subsample, Panel C of Table 2 shows the effect of the educational reform on the quantity of schooling for samples of men with different types of educational attainment. Column (3) confirms that the policy did not lead to additional schooling among cohorts of secondary school students. The point estimate is essentially zero and quite precisely estimated with a standard error of only 0.12 years of schooling. The remaining columns of panel $\mathrm{C}$ indicate no significant difference in years of

\footnotetext{
${ }^{24}$ That the proportion of men born in urban regions among those with vocational training did not change after the policy reform is also consistent with selection. While the most able among those who received vocational education prior to the policy change probably ended up completing the 2 nd level of lyceum, the least able may not have succeeded in progressing to vocational training which was available only at the higher track after the policy change.
} 
schooling for other levels and types of educational attainment (similar results are found with higher and primary education). These findings are consistent with the changes induced by the policy. According to the calculations discussed above, most students affected by the policy continued to higher-level vocational programs that lasted 1 year after completing 10 years of general education. Since these students would have completed 8 years of general education and 3 years of vocational training prior to the reform, they would not have experienced any change in quantity of schooling. These findings confirm that the policy altered the amount of vocational and general education while keeping the overall quantity of education approximately unchanged.

\section{Results}

\subsection{Cross-sectional analysis}

Before turning to the findings associated with the 1973 educational reform, we examine the standard cross-sectional relationship between vocational training and labor market outcomes. Table 3 presents these results, based on equation 1, using both census and household data. The sample is restricted to secondary-educated men born between 1956 and 1961 to correspond with the samples presented later. All regressions control for a cubic spline in month of birth, ethnicity, region of birth, urban/rural place of birth, and calendar month fixed effects while robust standard errors are clustered by month of birth.

The effect of vocational training on occupational outcomes is shown in columns (1) and (2) of panels A and B. These coefficients indicate that men with vocational training were significantly more likely to be employed as manual workers and craftsmen than their counterparts with general education. In particular, men with vocational training were approximately 23 percentage points more likely to be manual workers and 13 percentage points more likely 
to be craftsmen in 1992. Similar magnitudes are visible in the 2002 data, during the later stages of the transition period. ${ }^{25}$ Columns (3) and (4) of Table 3 show the effect of vocational training on labor market participation. Men with vocational training were 1.5 percentage points more likely to be unemployed in 1992 than men with general education. On a base of 6 percent unemployment, this represents a large and significant difference. ${ }^{26}$ Not surprisingly, since most men were employed in the labor force, the effect on nonemployment for men was similar to the effect on unemployment over this time period. The effect of vocational training on unemployment becomes even larger over time. By 2002, men with vocational training were 4.7 percentage points more likely to be unemployed. Finally, we examine the effect of vocational training on wages and income using the pooled LSMS data from 1995-2000. Column (1) of Panel C indicates that men with vocational training lived in households with lower family income while column (2) reveals that men with vocational training earned approximately 7 percent less than men with general education. ${ }^{27}$

Consistent with other studies from Romaina, we find that individuals with vocational training are more likely to be unemployed, exit from the labor force and earn lower wages than their counterparts with general education. ${ }^{28}$ We also confirm that individuals with vocational training are more likely to be employed in manual and craft-related occupations. Moreover, the adverse labor market outcomes become even more pronounced during the later

\footnotetext{
${ }^{25}$ The results for manual and craft occupations in the LSMS data are similar to those from the Census data.

${ }^{26}$ Though not shown, the effect of the covariates on unemployment generally accord with intuition. The coefficient on the month of birth trend is positive and significant reflecting that younger individuals are more likely to be unemployed. Men born in urban regions are significantly more likely to be unemployed. Finally, men with a Hungarian or Gypsy ethnic background are also significantly more likely to be unemployed compared to Romanians.

${ }^{27}$ Again, the effect of the covariates on this measure of wages is generally significant and consistent with previous findings. Men who were born later are employed in jobs that earn significantly less. Men born in urban areas are earning significantly more and those with non-Romanian ethnicity earn significantly less than Romanians.

${ }^{28}$ In light of the findings by Munich, Svejnar, and Terrell (2005), we examined whether the cross-sectional findings differed by type of firm ownership. We found no significant differences in the effect of vocational training on labor market outcomes for private and state-owned firms.
} 
stages of the transition. These results hold when examined separately in the period before and after January 1, 1959 or when we include cohort fixed effects to focus on the relationship within each cohort (not shown).

\subsection{Effect of the reform on labor market outcomes}

We examine the effect of the 1973 educational reform on labor market outcomes by estimating equation 2 from section 4. Columns (1) and (2) in panel A of Table 4 show the reduced-form effect of the 1973 educational reform on occupational outcomes in 1992. The coefficients on AFTER are highly significant, implying that the reform altered the occupational structure. Specifically, men in cohorts affected by the policy were 2.3 percentage points less likely to be employed in a manual occupation than their counterparts who were unaffected by the policy. Based on the calculations in section 4, the corresponding effect on the treated population is approximately 7 percentage points. ${ }^{29}$ Moreover, these estimates imply that an additional year of vocational training instead of general education increased the probability of being employed in a manual occupation by about 3 percentage points. The effect of the policy on the probability of becoming a craftsmen is even larger: about 3.4 percentage points which translates into a 10 percentage point effect on the treated population. In other words, the additional year of vocational training instead of general education increased the probability of working as a craftsman by over 4 percentage points. We also confirm that these findings hold for disaggregated occupations such as metal workers and clerks. ${ }^{30}$

Panels A and B of Figure 4 provide a graphical representation of the 1992 results. The

\footnotetext{
${ }^{29}$ This effect is somewhat smaller than expected based on the cross-sectional relationships between vocational training and manual occupations. However, these results need to be interpreted in the context of Romania's unique Communist "labor market". Even individuals with more general education may have been required to enter manual occupations when joining the labor force. Thus, the effect on their occupation in 1992 may have been muted due to their previous labor market experience.

${ }^{30}$ In the case of clerks, we find that men affected by the policy are more likely to be employed as clerks, consistent with the evidence that vocational training is associated with a lower probability of working as a clerk.
} 
raw fraction of secondary educated men employed as manual and craft workers in each month of birth are indicated with open circles while solid lines plot cubic functions of these outcomes on either side of the discontinuity. There is a clear break in the trend around the policy change for both occupational outcomes. Together with the regression results, these findings support our contention that the policy did not simply relabel schools from vocational to general lyceum schools. Panels A and B of Figure 5 also reveal a discontinuity in occupational outcomes using the 2002 Census. However, compared to estimates from 1992, the corresponding coefficients in panel B of Table 4 are smaller and insignificant. ${ }^{31}$ This change probably reflects the continuing reallocation of labor to new occupations during the transition period.

The reduced-form effect of the 1973 educational reform on labor market participation is shown in columns (3) and (4) of Table 4. The effect of the policy on the probability of being unemployed or nonemployed is small and insignificant in 1992, at the beginning of the transition period (panel A). Moreover, the effect of the policy is still insignificant in 2002, during the later stages of the transition period when general education may have become more valuable (panel B). The bottom panels of Figures 4, 5 and 6 confirm these findings in a graphical context. None of the panels reveal any discontinuity in labor market participation. Columns (1) and (2) of panel $\mathrm{C}$ show the effect of the policy on family income and log wages using household LSMS data from 1995-2000. These estimates are somewhat imprecise but the effect of the policy on earnings is insignificant. Panels A and B of Figure 6 also show the absence of any clear discontinuity. Taken together, these findings contrast sharply with those from the cross-sectional analysis. ${ }^{32}$ Based on results from the 1973 educational reform,

\footnotetext{
${ }^{31}$ The effects on occupational outcomes using the 1995-2000 household data (not shown for brevity) are similar in magnitude but somewhat less precise.

${ }^{32}$ Although manual and craft occupations are associated with higher unemployment and slightly higher wages, the shifts in occupational structure would not be sufficient to result in any substantial differences in labor market outcomes. Moreover, as we discuss in the section on robustness, much of the difference in the
} 
the reduction in vocational training did not cause an increase in labor market participation or earnings.

\subsection{The structural reforms of 1997}

The six yearly LSMS surveys from 1995-2000 allow us to focus on labor market outcomes immediately before and after the comprehensive macroeconomic stabilization and structural reform program of 1997. Table 5 presents the impact of these economic reforms on labor market outcomes by including an indicator for post 1997 surveys. The cross-sectional effects of vocational training on unemployment, nonemployment, family income and log wage are shown in Panel A. ${ }^{33}$ The coefficient on POST1997 indicates that the 1997 economic reforms worsened labor market outcomes for all men. Moreover, the coefficient on the interaction of vocational training and POST1997 is large and significant for three of the four outcomes, suggesting that the reforms hit vocationally trained individuals particularly hard. Panel B shows the effect of the educational reform of 1973 before and after the 1997 economic reforms. ${ }^{34}$ While the negative effect of the 1997 reforms is also visible in this specification, the coefficient on the interaction of AFTER and POST1997 is very small and statistically indistinguishable from zero. Thus, in contrast to cross-sectional regressions where the benefits of general education show an increase during the period of structural reforms, we do not find a corresponding effect in regressions that exploit the 1973 educational reform. We interpret these results as further evidence that the cross sectional relationship between vocational training and labor market success is driven by selection.

outcomes between vocational and general education occurs within occupations as well.

${ }^{33}$ Specifically, we estimate: outcome $e_{i}=\beta^{\prime} \mathbf{X}_{i}+v V O C_{i}+\gamma P O S T 1997_{i}+\pi V O C_{i} * P O S T 1997_{i}+f\left(c_{i}\right)+\varepsilon_{i}$

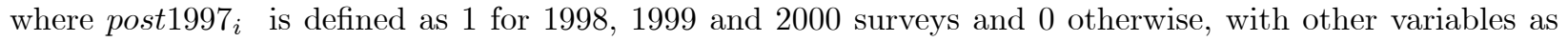
defined previously.

${ }^{34}$ In this instance, we estimate: outcome $_{i}=\beta^{\prime} \mathbf{X}_{i}+v A F T E R_{i}+\gamma P O S T 1997_{i}+\pi A F T E R_{i} * P O S T 1997_{i}+$ $f\left(c_{i}\right)+\varepsilon_{i}$. 


\subsection{The quality of general education}

The drastic expansion of general education in Romania so essential to credibly identifying the effect of vocational training may have caused a reduction in the quality of general education. Moreover, with an educational reform that affected such a large fraction of the school-age population, the question of how resources were allocated to implement the reform becomes extremely important. Appendix Figures 1 and 2 show the influx of teachers from vocational to general high school and indicate that the average student/faculty ratios across the two types of schools were largely maintained. Although we have some anecdotal evidence that retraining occurred, these teachers may nevertheless have been relatively inexperienced at teaching the new curriculum.

We perform two additional tests to examine possible changes in the quality of general education. ${ }^{35}$ First, we consider labor market outcomes restricted to individuals who completed general education (as opposed to any secondary education). If the quality of general education declined due to the policy, we expect that labor market outcomes would have been worse for cohorts affected by the policy. However, we find that labor market outcomes for individuals who completed general education are not significantly different before and after the introduction of the policy. Second, we examine whether labor market outcomes differ by region of birth. Since some regions experienced larger expansions in general education, students from these regions should also have been affected more by changes in the quality of education. However, we find no significant differences in labor market outcomes by region of birth for individuals who completed general school before and after the policy change. We conclude that a change in the quality of general education is unlikely to explain why cohorts who have received more general education after the 1973 educational reform do not have

\footnotetext{
${ }^{35}$ These robustness checks for changes in the quality of education are presented in more detail in an earlier version of this paper (Malamud and Pop-Eleches, 2005).
} 
better labor market outcomes.

\subsection{Robustness checks}

Our main results were based on a sample of individuals with a secondary education who were born between 1956 and 1961 and therefore within a 3 year window of the January 1, 1959 cutoff. Panel A of Appendix Table 1 confirms these results with all men, by including those with primary, gymnasium and higher education. In Panel B, we consider three alternative samples that extend or restrict the window around the cutoff, ranging from a 1 year window to a 4 year window. The effect of the reform on the probability of being employed as a manual or craft worker in 1992 remain unchanged. As expected, the standard errors are generally smaller in broader windows. Moreover, the effect of the policy on labor market participation and log wages later in the transition is not significant in any of the specifications. Panel C presents estimates using alternative polynomial functions of the forcing variable. Whether we use linear, quadratic or quartic splines, the coefficients on AFTER are large and significant for occupational outcomes and small and insignificant for the labor market outcomes. Using simple linear, quadratic, cubic, and quartic trends in month of birth does not affect our results in any substantial way (not shown here). Finally, Panel D shows reduced-form estimates around alternative year cutoffs. In essence, we consider "placebo experiments" around January 1 of the two preceding and two following years. We find no significant difference in the likelihood of being employed in a manual or craft-related occupation or in unemployment and wages using these alternative year cutoffs. ${ }^{36}$

In addition to these robustness checks, we also examined whether the differences in labor market outcomes between vocational and general secondary educated men could be driven

\footnotetext{
${ }^{36}$ Although not shown here, estimating the binary outcome variables using logit or probit functions does not alter any of our results. Moreover, we find similar results using non-parametric methods such as local linear regression.
} 
by occupation specific shocks. ${ }^{37}$ Since the old centralized sectors which employed most of the vocationally trained workers were hit hardest during the transition period, it is possible that occupation and industry specific shocks might be driving our results. We consider this alternative explanation with regressions that include controls for detailed indicators of previous occupation. While the size of the effect is slightly reduced in the cross-section, the effect of vocational training remains large and significant, implying that differences in labor market performance continue to hold within occupations. The reduced form results for the effect of the 1973 educational reform remain essentially unchanged. Hence, changes in labor demand for occupations associated with vocational training do not appear to explain our findings.

\section{Conclusion}

This paper examines the relative benefits of general education and vocational training in the context of a transition economy which experienced major technological and institutional change. We exploit an educational reform that occurred in Romania in 1973 to avoid the selection bias that arises because less able students are more likely to enroll in vocational programs. By requiring students born after January 1, 1959 to complete an additional two years of general education instead of entering vocational schools, the policy shifted about $15 \%$ of the students in secondary school from vocational to general lyceum schools within a single year. The policy also shortened the length of vocational courses so even students affected by the policy who continued on to vocational school after completing an additional two years of general education received less vocational training. Nevertheless, this policy change did not significantly alter average years of schooling across cohorts of secondary students. Using the

\footnotetext{
${ }^{37}$ These additional checks are presented in an earlier version of this paper (Malamud and Pop-Eleches, 2005).
} 
Romanian Censuses of 1992 and 2002 as well as LSMS household surveys from 1995-2000, we find evidence that men who were affected by the policy were less likely to work as manual workers and craftsmen than their counterparts who were born too early to be affected by the policy. However, we find no significant difference in labor market participation or earnings between cohorts that were affected and unaffected by the policy, even during the later stages of the transition period.

The findings associated with the 1973 educational reform are in sharp contrast to the cross-sectional evidence that individuals with vocational training are significantly more likely to be unemployed, out of the labor force, and have lower wages. We have argued that possible changes in the quality of general secondary education as a result of the policy are unlikely to explain why we do not observe the positive benefits of a general education. Hence, our findings suggest that the relationship between vocational training and labor market returns highlighted by previous studies may largely be a consequence of selection. It is important to note that these estimates are relevant for the marginal student shifted from vocational to general education rather than for the average student. But this group of marginal students is probably the most likely to be affected by any policy which encourages general education over vocational training. 


\section{References}

Acemoglu, D., and J.S. Pischke, "Why do Firms Train: Theory and Evidence," Quarterly Journal of Economics 113 (1998), 79-119.

Acemoglu, D., and J.S. Pischke, "Beyond Becker: Training in Imperfect Labor Markets," Economic Journal 109 (1999), 112-142.

Barberis, N, M. Boycko, A. Shleifer and N. Tsukanova, "How Does Privatization Work? Evidence from the Russian Shops," Journal of Political Economy 104:4 (1996), 764-790.

Bennel, P., "General versus Vocational Secondary Education in Developing Countries: A Review of the Rates of Return Evidence," Journal of Development Studies 33:2 (1996), $230-47$.

Blideanu, E., Invatamintul Secundar de Cultura Generala Din Diferite Tari (Editura Didactica si Pedagogica Bucuresti, 1972).

Brainerd, E., "Winners and Losers in Russia's Economic Transition," American Economic Review 88:5 (1998), 1094-1116.

Braham, R.L., Education in Romania: A Decade of Change (US Government Printing Press, 1972).

Braham, R.L., The Educational System of Romania (US Government Printing Press, 1978).

Card, D., Dobkin, C. and N. Maestas, "The Impact of Nearly Universal Insurance Coverage on Health Care Utilization and Health: Evidence from Medicare," NBER Working Paper No. 10365 (2004).

Dimitriu, E., Ionescu, O. Nica, I. and I. Orghidan, A Concise History of Education in Romania (Editura Stiintifica si Enciclopedica, 1981).

Dinardo, J. and D. Lee, "Economic Impacts of New Unionization on U.S. Private Sector Employers: 1984-2001," Quarterly Journal of Economics 119:4 (2004), 1383-1442.

Earle J.S., "Industrial Decline and Labor Reallocation in Romania," William Davidson Institute Working Paper 118 (1997).

Earle J.S. and C. Pauna, "Incidence and duration of unemployment in Romania," European Economic Review 40 (1996), 829-837.

Earle J.S. and C. Pauna, "Long-term unemployment, social assistance and labor market policies in Romania," Empirical Economics 23 (1998), 203-235.

Goldin, C., "The Human-Capital Century and American Leadership: Virtues of the Past," Journal of Economic History 61:2 (2001), 263-292. 
Grasso, J.T. and J.R. Shea, Vocational Education and Training: Impact on Youth (Berkeley, California: Carnegie Council on Policy Studies, 1979).

Hahn, J., Todd, P., and W. van der Klaauw, "Identification and Estimation of Treatment Effects with a Regression Discontinuity Design," Econometrica 69:1 (2001), 201-209.

Imbens, G.W. and J.D. Angrist, "Identification and Estimation of Local Average Treatment Effects," Econometrica 62:2 (1994), 467-475.

Krueger, D. and K. Kumar, "Skill-Specific rather then General Education: A Reason for US-Europe Growth Differences?" Journal of Economic Growth 9:2 (2004a), 167-207.

Krueger, D. and K. Kumar, "US-Europe Differences in Technology-Driven Growth: Quantifying the Role of Education," Journal of Monetary Economics 51:1 (2004b), 161-190.

Lechner, M., "An Evaluation of Public Sector Sponsored Continuous Vocational Training Programs in East Germany," Journal of Human Resources 35:2 (2000), 347-375.

Lee, D. and J. Mccrary, "Crime, Punishment, and Myopia," NBER Working Paper No. 11491 (2005).

Lee, D. and D. Card, "Regression Discontinuity Inference with Specification Error," Journal of Econometrics 142:2 (2007), 655-674.

Malamud O. and C. Pop-Eleches, "General Education vs. Vocational Training: Evidence from an Economy in Transition," Harris School Working Paper 05.16 (2005).

Meghir, C. and M. Palme, "Educational Reform, Ability and Parental Background," American Economic Review 95:1 (2005), 414-424.

Meyer, R.H., "Job training in the Schools," in Job Training for Youth, eds. R.E. Taylor, H. Rosen, and F.C. Pratzner (Columbus: The National Center for Research in Vocational Education, Ohio State University, 1982, 307-344).

Mincer, J., Schooling, Experience, and Earnings (New York: Columbia University Press, 1974).

Munich, D., Svejnar, J., and K. Terrel, "Returns to Human Capital under the Communist Wage Grid and during the Transition to a Market Economy," Review of Economics and Statistics 87:1 (2005), 100-123.

Nelson, R.R. and E.S. Phelps, "Investment in Humans, Technological Diffusion, and Economic Growth," American Economic Review 56:1/2 (1966), 69-75.

Nesporova, A., "Unemployment in Transition Economies" Economic Analysis Division Seminar Paper (United Nations Economic Commission for Europe, 2002).

Neuman, S. and A. Ziderman, "Vocational Schooling, Occupational Matching, and Labor Market Earnings in Israel," Journal of Human Resources 26:2 (1991), 256-281. 
Neuman, S. and A. Ziderman, "Vocational Education in Israel: Wage Effects fo the VocEdOccupation Match," Journal of Human Resources 34:2 (1999), 407-420.

OECD, Reviews of National Policies for Education: Romania (Paris: OECD, 2000a).

OECD, Labour Market and Social Policies in Romania (Paris: OECD, 2000b).

Porter, J., "Estimation in the Regression Discontinuity Model," mimeo, Department of Economics, University of Wisconsin (2003).

Romania Government, The Education Law of the Socialist Republic of Romania (Bucharest: Didactical and Pedagogical Publishing House, 1968).

Romania Government, Resolution of the Communist Party's Central Committee of June 18 and 19, 1973 (Bucharest: Editura Politica, 1973).

Romania Government, Presidential Decree Nr 191/1977 Article 25 (Bucharest: Offiical Bulletin Nr. 67, 1977).

Romania Government, Annual Statistics of the Socialist Republic of Romanian 1960-1980.

Romania Government, Statistics Yearbook 2004, http://www.insse.ro/download/anuar_2002.

UNESCO, Statistical Yearbook (Paris, France: 1969, 1975, 1981).

Voicu, A., "Employment Dynamics in the Romanian Labor Market: A Markov Chain Monte Carlo Approach," Journal of Comparative Economics 33:3 (2005), 604-639. 


\section{A Appendix}

As mentioned in the main text, we do not have precise information on the number of years of vocational training and the total years of schooling for each individual. Instead, we only have information on whether students completed the first stage of lyceum school, the second stage of lyceum school, or vocational school. ${ }^{38}$ The first and second stage of lyceum school are associated with 10 and 12 years of general education respectively. Following the 1973 educational reform, all students that completed vocational school also completed the first stage of lyceum school. These students therefore received 10 years of general education and 1 year of vocational training. However, prior to the 1974-75 school year, most students who completed vocational school would have received 8 years of general education and 3 years of vocational training. We cannot distinguish individuals who entered vocational school after grade 8 prior to the educational reform from those individuals who entered vocational schools after grade 10 and completed shorter vocational courses.

\section{A.1 Effect of the policy on the treated population}

We estimate the rough proportion of vocational students at each level using enrollment data from the Annual Statistics of the Socialist Republic of Romania. Assuming that there were no dropouts and that the number of students entering vocational school after grade 10 remained constant over time, we estimate that approximately 45 percent of the students with vocational training born in 1958 had entered vocational school after grade $8{ }^{39}$ Furthermore, we can estimate that approximately 40 percent of students that would have entered vocational school after grade 8 but for the policy reform, entered vocational school following grade 10 after completing an additional two years of general education. ${ }^{40}$ Including students who were in apprenticeship programs (which are counted jointly with vocational students in the 1992 Census), we need to adjust these calculations so that approximately 50 percent of

\footnotetext{
${ }^{38}$ In addition, we know whether they completed gymnasium (8 years of schooling), primary school (4 years of schooling) or some form of postsecondary schooling.

${ }^{39}$ Based on the enrollment data, approximately 250,000 students were enrolled in vocational schools in 1973-74 and 190,000 students were enrolled vocational schools in 1974-75. Since enrollment in 1973-74 includes three cohorts of students that entered after grade 8 whereas enrollment in 1974-75 only includes two cohorts of students that entered after grade 8 (in addition to a cohort of students that entered after grade 10 in each case), we can solve for the size of each cohort: 60,000 in the cohort that entered vocational after grade 8 and 70,000 in the cohort that entered vocational school after grade 10. Given these predicted sizes, we would expect the number of students enrolled in the following school year 1975-76 to equal 130,000 (which is not too far from the actual figure of 123,000).

${ }^{40}$ Enrollment in vocational schools in 1976-77 was approximately 94,000. Although no more cohorts of students who entered vocational school after grade 8 should remain, students who would have wished to enter vocational school after grade 8 in 1974-75 could now enter after having completed grade 10 in general school. Since the numbers of students entering vocational school after grade 10 is assumed to remain constant, we can calculate that approximately 24,000 out of 60,000 students who were denied entrance in vocational school after grade 8 decided to continue on to vocational school after completing their additional two years of general education. Assuming that a similar proportion wished to continue into vocational school from the second and third cohorts after the policy reform, we would expect the number of students enrolled in the years 1977-78 and 1978-79 to be equal to 118,000 and 142,000 respectively (which is not too far from the actual figures of 114,000 and 138,000 ).
} 
the students with vocational training or apprenticeships in 1958 were affected by the policy and about 45 percent of these students continued onto these programs after completing their additional two years of general education following the reform. ${ }^{41}$ Given these numbers, we expect that the size of the cohort of students completing vocational training or apprenticeship programs of 1959 was about 75 percent of the size of the cohort of 1958, which is almost exactly what find in the data from the 1992 Census. Hence, we conclude that about 50 percent of the students with vocational training before 1959 - or 33 percent of the students with secondary education - were affected by the policy. Consequently, we would need to scale up the reduced-form estimate over all secondary educated individuals by a factor of 3 to derive an estimate of the policy on the treated population.

\section{A.2 Effect of vocational training (LATE)}

We can provide some rough calculations on the average difference in vocational training before and after the policy change by comparing cohorts of individuals born in 1958 and 1959 using data from the 1992 Census. Based on this data, the number of students completing the first and second level of lyceum schools increased by about 4 and 11 percentage points respectively while the number of students completing vocational school fell by about 15 percentage points. Moreover, according to the calculations of the previous section, the number of students completing vocational school after having attended the first level of lyceum school increased by about 18 percentage points after the policy. ${ }^{42}$ These estimates suggest that, among secondary educated individuals, the average decrease in vocational training was 0.8 years. Now, rather than scaling the reduced-form estimate of the effect of the policy by the proportion of individuals who were affected by the policy, we can scale the reduced-form estimate by the average change in vocational training induced by the policy. In other words, we can calculate the local average treatment effect (LATE) of a year of vocational versus general education. We can express an estimate of this effect as follows: ${ }^{43}$

$$
E\left[\text { outcome }_{i} \mid V_{i}\right]=\frac{E\left[\text { outcome }_{i} \mid A F T E R_{i}=1\right]-E\left[\text { outcome }_{i} \mid A F T E R_{i}=0\right]}{E\left[V_{i} \mid A F T E R_{i}=1\right]-E\left[V_{i} \mid A F T E R_{i}=0\right]}
$$

Conditional on observable characteristics, $\mathbf{X}_{i}$, the numerator of this expression is simply $\delta$ from equation 2. The denominator of the expression is the difference in the average quantity

\footnotetext{
${ }^{41}$ We employ a similar method is to derive the number of students in apprenticeship programs: Given enrollments of about 100,000 and 70,000 students in apprenticeships in 1973-74 and 1974-75 respectively, we calculate that approximately 30,000 students entered after grade 8 and 10,000 entered after grade 10. However, we also need to account for the secular decline in apprenticeships over time so that predictions of following years are adjusted accordingly.

${ }^{42}$ Those calculations suggest that approximately 50 percent of the students with vocational training in 1958 were affected by the policy and about 45 percent of these students entered vocational schools after completing the first stage of lyceum schools. Since about 65 percent of secondary educated students received vocational training in 1958, the number of students completing vocational school after first level of lyceum education decreased by 18 percentage points.

${ }^{43}$ See Imbens and Angrist (1994) for the assumptions that underly estimates of LATE. In particular, we need to assume a version of their montonicity requirement if we wish to allow for non-constant treatment effects.
} 
of vocational training between individuals in cohorts that were affected by the educational reform and their counterparts in cohorts that were unaffected. Applying the calculations above, we can conclude that the effect of an additional year of vocational training instead of general education on labor market outcomes approximately $1.25 \delta$. Note that the standard method for estimating this expression is by two-stage least squares (2SLS). However, given the data limitations, we have had to resort to this rather indirect approach. 
Table 1: Descriptive Statistics

\begin{tabular}{|c|c|c|c|c|c|c|}
\hline & \multicolumn{3}{|c|}{ Entire sample } & \multicolumn{3}{|c|}{ Secondary-educated sample } \\
\hline & Mean & SD & $\mathrm{N}$ & Mean & SD & $\mathrm{N}$ \\
\hline \multicolumn{7}{|l|}{ Panel A: 1992 Census } \\
\hline Urban region of birth & 0.283 & 0.451 & 227,446 & 0.268 & 0.443 & 143,417 \\
\hline Romanian & 0.896 & 0.305 & 227,446 & 0.911 & 0.285 & 143,417 \\
\hline Hungarian & 0.066 & 0.248 & 227,446 & 0.068 & 0.252 & 143,417 \\
\hline Gypsy & 0.020 & 0.139 & 227,446 & 0.005 & 0.071 & 143,417 \\
\hline \multicolumn{7}{|l|}{ Education level } \\
\hline Lower (primary/ gymnasium) & 0.255 & 0.436 & 227,446 & - & - & - \\
\hline Vocational & 0.359 & 0.480 & 227,446 & 0.570 & 0.495 & 143,417 \\
\hline Lyceum 9-12 & 0.271 & 0.445 & 227,446 & 0.430 & 0.495 & 143,417 \\
\hline Higher (postsec/university) & 0.114 & 0.318 & 227,446 & - & - & - \\
\hline \multicolumn{7}{|l|}{ Labor market outcomes } \\
\hline Manual worker & 0.780 & 0.414 & 216,342 & 0.839 & 0.367 & 138,924 \\
\hline Craft worker & 0.432 & 0.495 & 216,342 & 0.518 & 0.500 & 138,924 \\
\hline Unemployed & 0.066 & 0.249 & 219,652 & 0.057 & 0.232 & 140,305 \\
\hline Nonemployed & 0.098 & 0.298 & 227,446 & 0.077 & 0.267 & 143,417 \\
\hline \multicolumn{7}{|l|}{ Panel B: 2002 Census } \\
\hline Urban region of birth & 0.314 & 0.464 & 87,249 & 0.298 & 0.458 & 53,602 \\
\hline Romanian & 0.900 & 0.300 & 87,249 & 0.912 & 0.283 & 53,602 \\
\hline Hungarian & 0.063 & 0.243 & 87,249 & 0.069 & 0.253 & 53,602 \\
\hline Gypsy & 0.019 & 0.137 & 87,249 & 0.005 & 0.069 & 53,602 \\
\hline \multicolumn{7}{|l|}{ Education level } \\
\hline Lower (primary/gymnasium) & 0.234 & 0.423 & 87,249 & - & - & - \\
\hline Vocational & 0.359 & 0.480 & 87,249 & 0.584 & 0.493 & 53,602 \\
\hline Lyceum 9-12 & 0.255 & 0.436 & 87,249 & 0.416 & 0.493 & 53,602 \\
\hline Higher (postsec/university) & 0.152 & 0.359 & 87,249 & - & - & - \\
\hline \multicolumn{7}{|l|}{ Labor market outcomes } \\
\hline Manual worker & 0.719 & 0.449 & 74,758 & 0.799 & 0.401 & 46,699 \\
\hline Craft worker & 0.357 & 0.479 & 74,758 & 0.456 & 0.498 & 46,699 \\
\hline Unemployed & 0.116 & 0.320 & 75,850 & 0.121 & 0.326 & 47,261 \\
\hline Nonemployed & 0.231 & 0.422 & 87,249 & 0.225 & 0.417 & 53,602 \\
\hline \multicolumn{7}{|l|}{ Panel C: LSMS 1995-2000 } \\
\hline \multicolumn{7}{|l|}{ Education level } \\
\hline Lower (primary/gymnasium) & 0.172 & 0.377 & 28,395 & - & - & - \\
\hline Vocational & 0.385 & 0.487 & 28,395 & 0.567 & 0.495 & 19,286 \\
\hline Lyceum 9-12 & 0.294 & 0.456 & 28,395 & 0.433 & 0.495 & 19,286 \\
\hline Higher (postsec/university) & 0.149 & 0.356 & 28,395 & - & - & - \\
\hline \multicolumn{7}{|l|}{ Labor market outcomes } \\
\hline Log family income & 15.519 & 0.816 & 28,291 & 15.527 & 0.736 & 19,227 \\
\hline Log wages & 15.336 & 0.552 & 18,523 & 15.263 & 0.503 & 13,133 \\
\hline Unemployed & 0.115 & 0.319 & 26,973 & 0.123 & 0.328 & 18,459 \\
\hline Nonemployed & 0.159 & 0.365 & 28,389 & 0.160 & 0.367 & 19,282 \\
\hline
\end{tabular}

Notes: SD is the standard deviation and $\mathrm{N}$ is the sample size. All summary statistics based on cohorts born between 1956 and 1961 (within 3 years of January 1, 1959). The sample of secondary-educated men includes individuals with vocational and general secondary education only. Manual worker is defined as 1 for men employed in an occupation with ISCO category 5-9, and 0 if otherwise employed. Craft worker is defined as 1 for men employed in an occupation with ISCO category 7, and 0 if otherwise employed. Unemployed is defined as 1 for men actively seeking work, and 0 if employed. Nonemployment is defined as 1 for men not employed (unemployed or out of the labor force) and 0 otherwise. Log wages and log family income are based on annual wages and family income. 
Table 2: Effect of the 1973 Educational Reform on Educational Outcomes, Urban Status, and Years of Schooling

\begin{tabular}{lccc}
\hline \hline \multicolumn{3}{l}{ Panel A: Highest educational level achieved (out of the entire sample) } \\
Dependent variable & $\begin{array}{c}\text { Vocational } \\
(1)\end{array}$ & $\begin{array}{c}\text { General } \\
(2)\end{array}$ & $\begin{array}{c}\text { Secondary } \\
(3)\end{array}$ \\
\hline AFTER & $-0.080^{* *}$ & $0.070^{* *}$ & -0.009 \\
& {$[0.007]$} & {$[0.006]$} & {$[0.006]$} \\
$\mathrm{R}^{2}$ & 0.04 & 0.04 & 0.03 \\
Sample Size & 314,695 & 314,695 & 314,695 \\
Mean of dep. variable & 0.36 & 0.26 & 0.62 \\
\hline
\end{tabular}

\section{Panel B: Born in an Urban Area (dependent variable)}

\begin{tabular}{|c|c|c|c|c|}
\hline \multirow{2}{*}{ Sample restricted to: } & \multicolumn{3}{|c|}{ Secondary school level } & \multirow{2}{*}{$\begin{array}{c}\text { Entire sample } \\
\text { (4) }\end{array}$} \\
\hline & $\begin{array}{l}\text { Vocational } \\
\text { (1) }\end{array}$ & $\begin{array}{c}\text { General } \\
\text { (2) }\end{array}$ & $\begin{array}{l}\text { All } \\
\text { (3) }\end{array}$ & \\
\hline AFTER & $\begin{array}{c}-0.016 \\
{[0.010]}\end{array}$ & $\begin{array}{c}-0.061^{* *} \\
{[0.017]}\end{array}$ & $\begin{array}{c}-0.017 \\
{[0.011]}\end{array}$ & $\begin{array}{l}-0.012 \\
{[0.009]}\end{array}$ \\
\hline $\mathrm{R}^{2}$ & 0.08 & 0.15 & 0.12 & 0.13 \\
\hline Sample Size & 112,988 & 84,031 & 197,091 & 314,695 \\
\hline Mean of dep. variable & 0.20 & 0.34 & 0.26 & 0.27 \\
\hline
\end{tabular}

\section{Panel C: Years of Schooling (dependent variable)}

\begin{tabular}{lcccc} 
Sample restricted to & \multicolumn{3}{c}{ Secondary school level } & Entire sample \\
\cline { 2 - 4 } & Vocational & General & All & $(3)$ \\
\hline AFTER & $(1)$ & $(2)$ & 0.018 & -0.159 \\
& -0.198 & -0.076 & {$[0.118]$} & {$[0.176]$} \\
$\mathrm{R}^{2}$ & {$[0.130]$} & {$[0.143]$} & & \\
Sample Size & & & 0.01 & 0.07 \\
Mean of dep. variable & 0.02 & 0.04 & 2,930 & 4,532 \\
\hline \hline
\end{tabular}

Notes: Robust standard errors clustered by month of birth in brackets. ** and * indicate statistical significance at the 1 and 5 percent level respectively. Samples include all cohorts born between January 1, 1956 and December 31, 1961. AFTER is defined as 1 for individuals born on or after January 1, 1959 and 0 for individuals born on or before December 31, 1958. Columns in Panel A refer to different dependent variables (secondary education, general education, or vocational education). Columns in Panels B and C refer to sample restrictions (all men with secondary schooling, men with vocational education, men with general education, and the entire sample). All regressions include a cubic polynomial in month of birth fully interacted with AFTER and fixed effects for calendar of month. Binary outcome variables are estimated using a linear probability model. Data for Panels A and B uses combined data from 1992 and 2002 Census. Data for Panel C uses data from the 1995 and 1996 LSMS. Demographic controls for the 1992 and 2002 Census regressions include ethnicity, region of birth, and an indicator for urban or rural place of birth. Controls for the LSMS regressions include ethnicity, region of birth and dummies for year of survey. 
Table 3: Effect of Vocational Training on Labor Market Outcomes: Cross-sectional results

Panel A: 1992 Census

\begin{tabular}{lcccc} 
& $\begin{array}{c}\text { Manual worker } \\
(1)\end{array}$ & $\begin{array}{c}\text { Craft worker } \\
(2)\end{array}$ & $\begin{array}{c}\text { Unemployed } \\
(3)\end{array}$ & $\begin{array}{c}\text { Nonemployed } \\
(4)\end{array}$ \\
\cline { 2 - 5 } VOC & $0.235^{* *}$ & $0.135^{* *}$ & $0.015^{* *}$ & $0.013^{* *}$ \\
& {$[0.005]$} & {$[0.006]$} & {$[0.001]$} & {$[0.001]$} \\
$\mathrm{R}^{2}$ & & & & \\
Sample Size & 0.11 & 0.02 & 0.01 & 0.01 \\
Mean of dep. Variable & 138,924 & 138,924 & 140,305 & 143,417 \\
& 0.84 & 0.52 & 0.06 & 0.08
\end{tabular}

Panel B: 2002 Census

\begin{tabular}{lcccc} 
& $\begin{array}{c}\text { Manual worker } \\
(1)\end{array}$ & $\begin{array}{c}\text { Craft worker } \\
(2)\end{array}$ & $\begin{array}{c}\text { Unemployed } \\
(3)\end{array}$ & $\begin{array}{c}\text { Nonemployed } \\
(4)\end{array}$ \\
\cline { 2 - 5 } VOC & $0.260^{* *}$ & $0.109 * *$ & $0.047 * *$ & $0.050^{* *}$ \\
& {$[0.005]$} & {$[0.006]$} & {$[0.003]$} & {$[0.004]$} \\
$\mathrm{R}^{2}$ & & & & \\
Sample Size & 0.12 & 0.02 & 0.02 & 0.01 \\
Mean of dep. variable & 46,699 & 46,699 & 47,261 & 53,602 \\
& 0.80 & 0.46 & 0.12 & 0.22
\end{tabular}

Panel C: LSMS 1995-2000

\begin{tabular}{lcccc} 
& $\begin{array}{c}\text { Log family income } \\
(1)\end{array}$ & $\begin{array}{c}\text { Log wages } \\
(2)\end{array}$ & $\begin{array}{c}\text { Unemployed } \\
(3)\end{array}$ & $\begin{array}{c}\text { Nonemployed } \\
(4)\end{array}$ \\
\cline { 2 - 5 } VOC & $-0.146^{* *}$ & $-0.073^{* *}$ & $0.028^{* *}$ & $0.031^{* *}$ \\
& {$[0.016]$} & {$[0.012]$} & {$[0.006]$} & {$[0.007]$} \\
$\mathrm{R}^{2}$ & & & & \\
Sample Size & 0.06 & 0.1 & 0.02 & 0.02 \\
Mean of dep. variable & 14,519 & 10,102 & 14,046 & 14,555 \\
\hline \hline
\end{tabular}

Notes: Robust standard errors clustered by month of birth in brackets. ** and * indicate statistical significance at the 1 and 5 percent level, respectively. Samples include cohorts with a secondary-level education born between January 1, 1956 and December 31, 1961. VOC is defined as 1 if an individual completed a course in vocational training and 0 otherwise. All regressions include a cubic polynomial in month of birth and fixed effects for calendar of month. Panel A uses data from the 1992 Census; Panel B uses data from the 2002 Census and Panel C uses data from the 1995-2000 Romanian LSMS. Binary outcome variables are estimated using a linear probability model. Demographic controls for the 1992 and 2002 Census regressions include ethnicity, region of birth, and an indicator for urban or rural place of birth. Controls for the LSMS regressions include ethnicity, region of birth and dummies for year of survey. 
Table 4: Effect of the 1973 Educational Reform on Labor Market Outcomes: Reduced-form results

Panel A: 1992 Census

\begin{tabular}{lcccc} 
& $\begin{array}{c}\text { Manual worker } \\
(1)\end{array}$ & $\begin{array}{c}\text { Craft worker } \\
(2)\end{array}$ & $\begin{array}{c}\text { Unemployed } \\
(3)\end{array}$ & $\begin{array}{c}\text { Nonemployed } \\
(4)\end{array}$ \\
\cline { 2 - 5 } AFTER & $-0.023^{* *}$ & $-0.034^{* *}$ & 0.005 & 0.007 \\
& {$[0.007]$} & {$[0.010]$} & {$[0.004]$} & {$[0.005]$} \\
$\mathrm{R}^{2}$ & & & & \\
Sample Size & 0.02 & 0.01 & 0.01 & 0.01 \\
Mean of dep. Variable & 138,924 & 138,924 & 140,305 & 143,417 \\
& 0.84 & 0.52 & 0.06 & 0.08
\end{tabular}

Panel B: 2002 Census

\begin{tabular}{lcccc} 
& $\begin{array}{c}\text { Manual worker } \\
(1)\end{array}$ & $\begin{array}{c}\text { Craft worker } \\
(2)\end{array}$ & $\begin{array}{c}\text { Unemployed } \\
(3)\end{array}$ & $\begin{array}{c}\text { Nonemployed } \\
(4)\end{array}$ \\
\cline { 2 - 5 } AFTER & -0.014 & -0.001 & -0.001 & 0.004 \\
& {$[0.021]$} & {$[0.022]$} & {$[0.009]$} & {$[0.011]$} \\
$\mathrm{R}^{2}$ & & & & \\
Sample Size & 0.02 & 0.01 & 0.01 & 0.01 \\
Mean of dep. variable & 46,699 & 46,699 & 47,261 & 53,602 \\
& 0.80 & 0.46 & 0.12 & 0.22
\end{tabular}

Panel C: LSMS 1995-2000

\begin{tabular}{lcccc} 
& $\begin{array}{c}\text { Log family income } \\
(1)\end{array}$ & $\begin{array}{c}\text { Log wages } \\
(2)\end{array}$ & $\begin{array}{c}\text { Unemployed } \\
(3)\end{array}$ & $\begin{array}{c}\text { Nonemployed } \\
(4)\end{array}$ \\
\cline { 2 - 5 } AFTER & 0.041 & -0.01 & 0.029 & 0.016 \\
& {$[0.078]$} & {$[0.045]$} & {$[0.021]$} & {$[0.025]$} \\
$\mathrm{R}^{2}$ & & & & \\
Sample Size & 0.05 & 0.09 & 0.02 & 0.02 \\
Mean of dep. variable & 14,519 & 10,102 & 14,046 & 14,555 \\
\hline \hline
\end{tabular}

Notes: Robust standard errors clustered by month of birth in brackets. ** and * indicate statistical significance at the 1 and 5 percent level, respectively. Samples include cohorts with a secondary-level education born between January 1, 1956 and December $31,1961$. AFTER is defined as 1 for individuals born on or after January 1, 1959 and 0 for individuals born on or before December 31, 1958. All regressions include a cubic polynomial in month of birth fully interacted with AFTER and fixed effects for calendar of month. Panel A uses data from the 1992 Census; panel B uses data from the 2002 Census and Panel C uses data from the 1995-2000 Romanian LSMS. Binary outcome variables are estimated using a linear probability model. Demographic controls for the 1992 and 2002 Census regressions include ethnicity, region of birth, and an indicator for urban or rural place of birth. Controls for the LSMS regressions include ethnicity, region of birth and dummies for year of survey. 
Table 5: Effect of the 1997 Structural Reform Program on Labor Market Outcomes (LSMS samples)

Unemployed Nonemployed Log family income Log wages

Panel A: OLS

(1)

(2)

(3)

(4)

VOC

$\begin{array}{cccc}0.013 & 0.016 & -0.104^{* *} & -0.043^{* *} \\ {[0.007]} & {[0.008]} & {[0.021]} & {[0.013]}\end{array}$

POST1997

$0.043^{*}$

$-0.287 * *$

$-0.204^{* *}$

[0.012]

[0.014]

[0.029]

[0.018]

VOC*POST1997

$\begin{array}{lccc}0.028 * & 0.028 & -0.082 * * & -0.062 * * \\ {[0.013]} & {[0.015]} & {[0.029]} & {[0.020]}\end{array}$

$\mathrm{R}^{2}$

0.02

0.02

0.06

0.1

Sample Size

14,046

14,555

14,519

10,102

Mean of dep. variable

0.12

0.16

15.53

15.26

Panel B: Reduced form

\begin{tabular}{lcccc} 
& $\begin{array}{c}\text { Unemployed } \\
(1)\end{array}$ & $\begin{array}{c}\text { Nonemployed } \\
(2)\end{array}$ & $\begin{array}{c}\text { Log family income } \\
(3)\end{array}$ & $\begin{array}{c}\text { Log wages } \\
(4)\end{array}$ \\
\cline { 2 - 5 } AFTER & 0.024 & 0.02 & 0.046 & -0.011 \\
& {$[0.020]$} & {$[0.024]$} & {$[0.080]$} & {$[0.047]$} \\
POST1997 & $0.054^{* *}$ & $0.078^{* *}$ & $-0.331^{* *}$ & $-0.240^{* *}$ \\
& {$[0.013]$} & {$[0.015]$} & {$[0.024]$} & {$[0.019]$} \\
AFTER*POST1997 & 0.009 & -0.007 & -0.008 & 0.001 \\
& {$[0.013]$} & {$[0.014]$} & {$[0.026]$} & {$[0.020]$} \\
$\mathrm{R}^{2}$ & & & & \\
Sample Size & 0.02 & 0.02 & 0.05 & 0.09 \\
Mean of dep. variable & 14,046 & 14,555 & 14,519 & 10,102 \\
\hline \hline
\end{tabular}

Notes: Robust standard errors clustered by month of birth in brackets. ** and * indicate statistical significance at the 1 and 5 percent level respectively. Samples include cohorts with a secondary-level education born between January 1, 1956 and December 31, 1961. AFTER is defined as 1 for individuals born on or after January 1, 1959 and 0 for individuals born on or before December 31, 1958. VOC is defined as 1 if an individual completed a course in vocational training and 0 otherwise. POST1997 is defined as 1 if the observation is from LSMS surveys after 1997, the starting year of a macroeconomic stabilization and structural reform program. All regressions include a cubic polynomial in month of birth fully interacted with AFTER and fixed effects for calendar of month. Binary outcome variables are estimated using a linear probability model. Demographic controls include ethnicity and region of birth. 


Manual '92 $\quad$ Craftsmen '92 $\quad$ Unemployed ‘02 $\quad$ Nonemployed '02

(1)

(2)

(3)

(4)

Log wages

\section{Panel A: Alternative samples}

\begin{tabular}{lccccc} 
Baseline & $-0.023^{* *}$ & $-0.034^{* *}$ & -0.001 & 0.004 & -0.010 \\
& {$[0.007]$} & {$[0.010]$} & {$[0.009]$} & {$[0.011]$} & {$[0.045]$} \\
\multirow{3}{*}{ All men } & $-0.024^{* *}$ & $-0.031^{* *}$ & -0.008 & -0.011 & 0.042 \\
& {$[0.007]$} & {$[0.010]$} & {$[0.009]$} & {$[0.010]$} & {$[0.058]$}
\end{tabular}

Panel B: Alternative windows

\begin{tabular}{|c|c|c|c|c|c|}
\hline 1 year window & $\begin{array}{c}-0.041^{* *} \\
{[0.010]}\end{array}$ & $\begin{array}{c}-0.041^{* *} \\
{[0.012]}\end{array}$ & $\begin{array}{c}-0.019 \\
{[0.017]}\end{array}$ & $\begin{array}{c}0.011 \\
{[0.016]}\end{array}$ & $\begin{array}{c}0.016 \\
{[0.042]}\end{array}$ \\
\hline 2 year window & $\begin{array}{c}-0.033^{* *} \\
{[0.012]}\end{array}$ & $\begin{array}{c}-0.042 * \\
{[0.017]}\end{array}$ & $\begin{array}{c}-0.004 \\
{[0.012]}\end{array}$ & $\begin{array}{c}0.029 * \\
{[0.011]}\end{array}$ & $\begin{array}{c}0.063 \\
{[0.059]}\end{array}$ \\
\hline 4 year window & $\begin{array}{c}-0.023 * * \\
{[0.006]}\end{array}$ & $\begin{array}{c}-0.029 * * \\
{[0.009]}\end{array}$ & $\begin{array}{c}0.008 \\
{[0.009]}\end{array}$ & $\begin{array}{l}-0.001 \\
{[0.010]}\end{array}$ & $\begin{array}{l}-0.044 \\
{[0.040]}\end{array}$ \\
\hline
\end{tabular}

Panel C: Alternative trends

$\begin{array}{lccccc}\text { Linear } & -0.020^{* *} & -0.033^{* *} & 0.000 & 0.001 & 0.015 \\ & {[0.003]} & {[0.005]} & {[0.005]} & {[0.005]} & {[0.021]} \\ \text { Quadratic } & -0.023^{* *} & -0.029^{* *} & 0.006 & -0.002 & -0.033 \\ & {[0.004]} & {[0.007]} & {[0.007]} & {[0.008]} & {[0.031]} \\ \text { Quartic } & -0.024^{* *} & -0.044^{* *} & 0.004 & 0.024^{*} & 0.007 \\ & {[0.008]} & {[0.013]} & {[0.011]} & {[0.011]} & {[0.054]}\end{array}$

\section{Panel D: Placebo year cutoffs}

\begin{tabular}{lccccc}
1957 & 0.005 & 0.021 & 0.006 & -0.018 & -0.075 \\
& {$[0.008]$} & {$[0.012]$} & {$[0.007]$} & {$[0.010]$} & {$[0.045]$} \\
1958 & 0.009 & 0 & -0.001 & 0.014 & 0.009 \\
& {$[0.010]$} & {$[0.013]$} & {$[0.010]$} & {$[0.011]$} & {$[0.045]$} \\
1959 & $-0.023^{* *}$ & $-0.034^{* *}$ & -0.001 & 0.004 & -0.010 \\
& {$[0.007]$} & {$[0.010]$} & {$[0.009]$} & {$[0.011]$} & {$[0.045]$} \\
1960 & 0.004 & 0.02 & 0.005 & 0.003 & -0.016 \\
& {$[0.007]$} & {$[0.014]$} & {$[0.010]$} & {$[0.010]$} & {$[0.047]$} \\
1961 & 0.005 & -0.005 & 0.010 & -0.002 & $0.094^{*}$ \\
& {$[0.007]$} & {$[0.013]$} & {$[0.012]$} & {$[0.014]$} & {$[0.044]$} \\
\hline \hline
\end{tabular}

Notes: Robust standard errors clustered by month of birth in brackets. ** and * indicate statistical significance at the 1 and 5 percent level respectively. Binary outcome variables are estimated using a linear probability model. Panels A, B, and D include a cubic polynomial in month of birth fully interacted with AFTER. All regressions include calendar of month dummies (except regressions using 1 year window due to colinearity). Columns (1), and (2) use data from the 1992 Census; columns (3), and (4) use data from the 2002 Census and column (5) uses data from the 1995-2000 Romanian LSMS. Demographic controls for the 1992 and 2002 Census regressions include ethnicity, region of birth, and an indicator for urban or rural area of birth. Controls for the LSMS regressions include ethnicity, region of birth and dummies for year of survey. 
Figure 1: Structure of Education in Romaina

Panel A: Before 1973 (Individuals born before January 1, 1959)

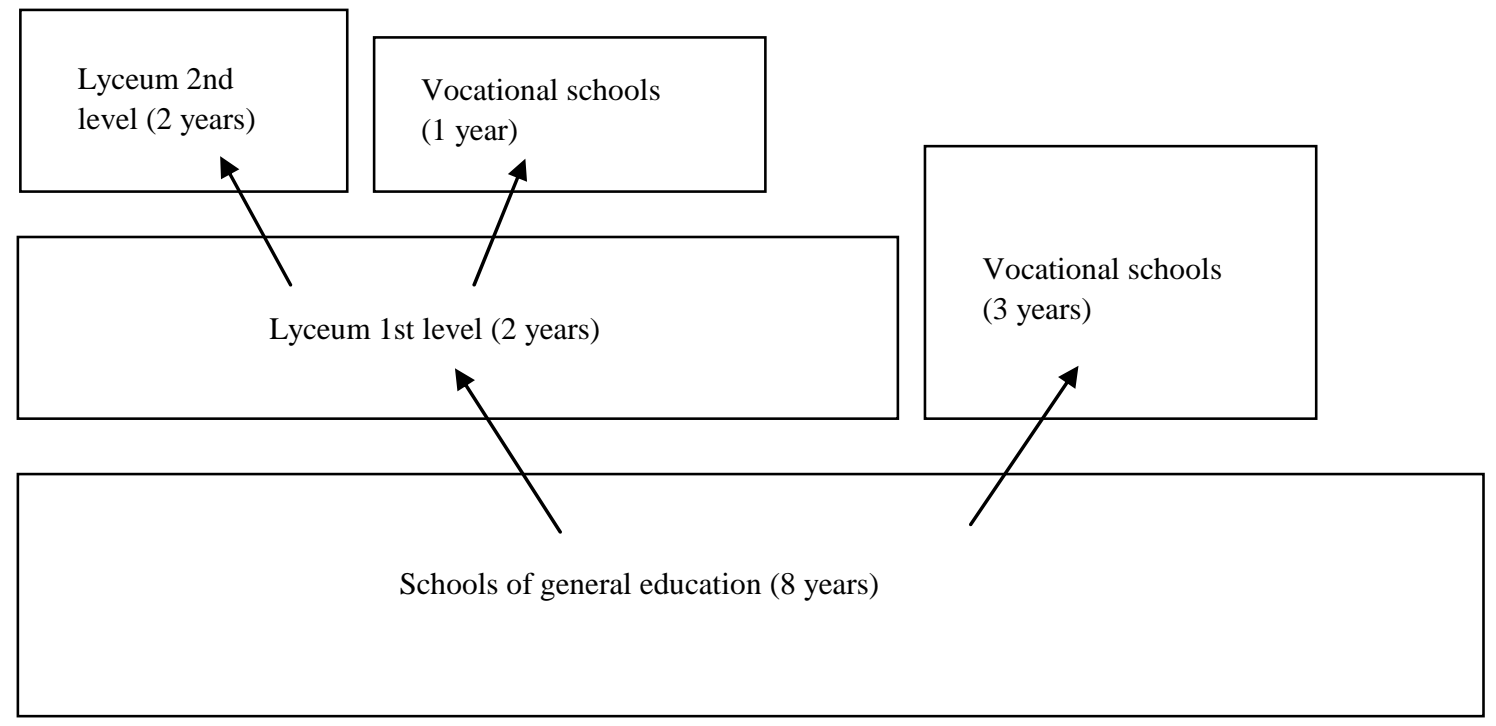

Panel B: After 1973 (Individuals born after January 1, 1959)

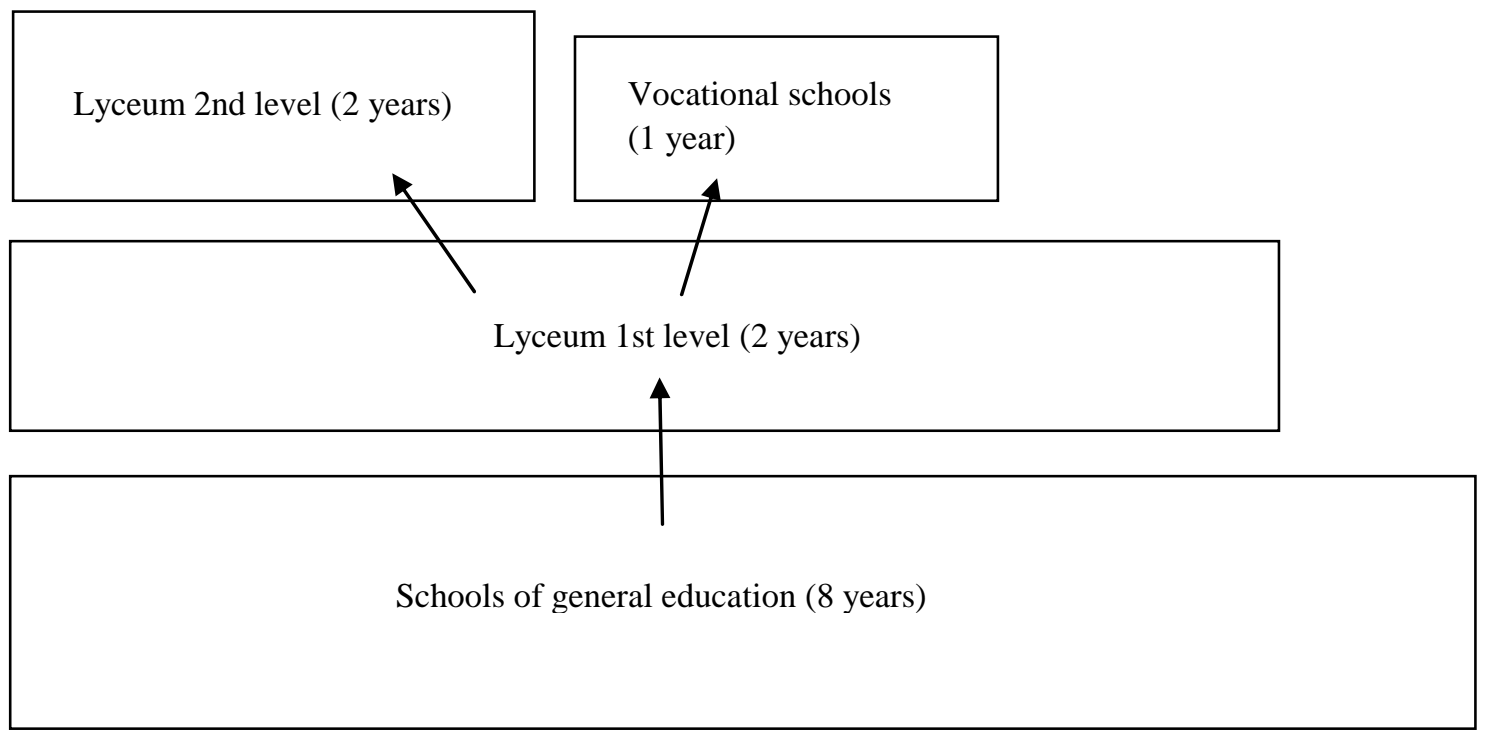

Source: Braham (1978) 
Figure 2: Educational Attainment by Birth Cohort

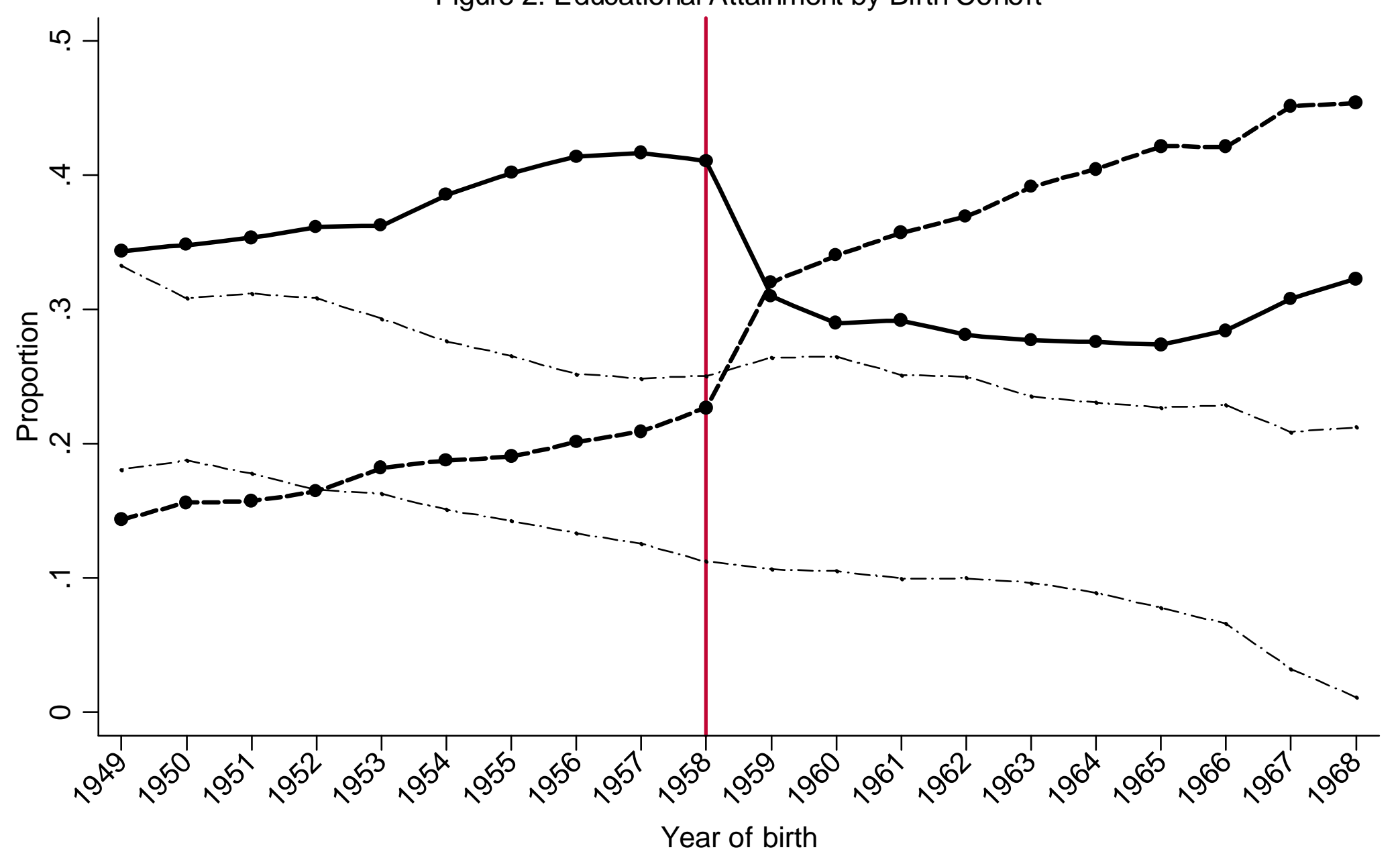

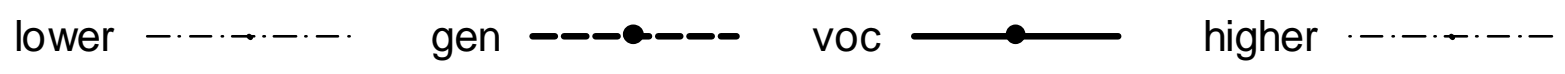


Figure 3: Proportion in Vocational Training and Secondary Level
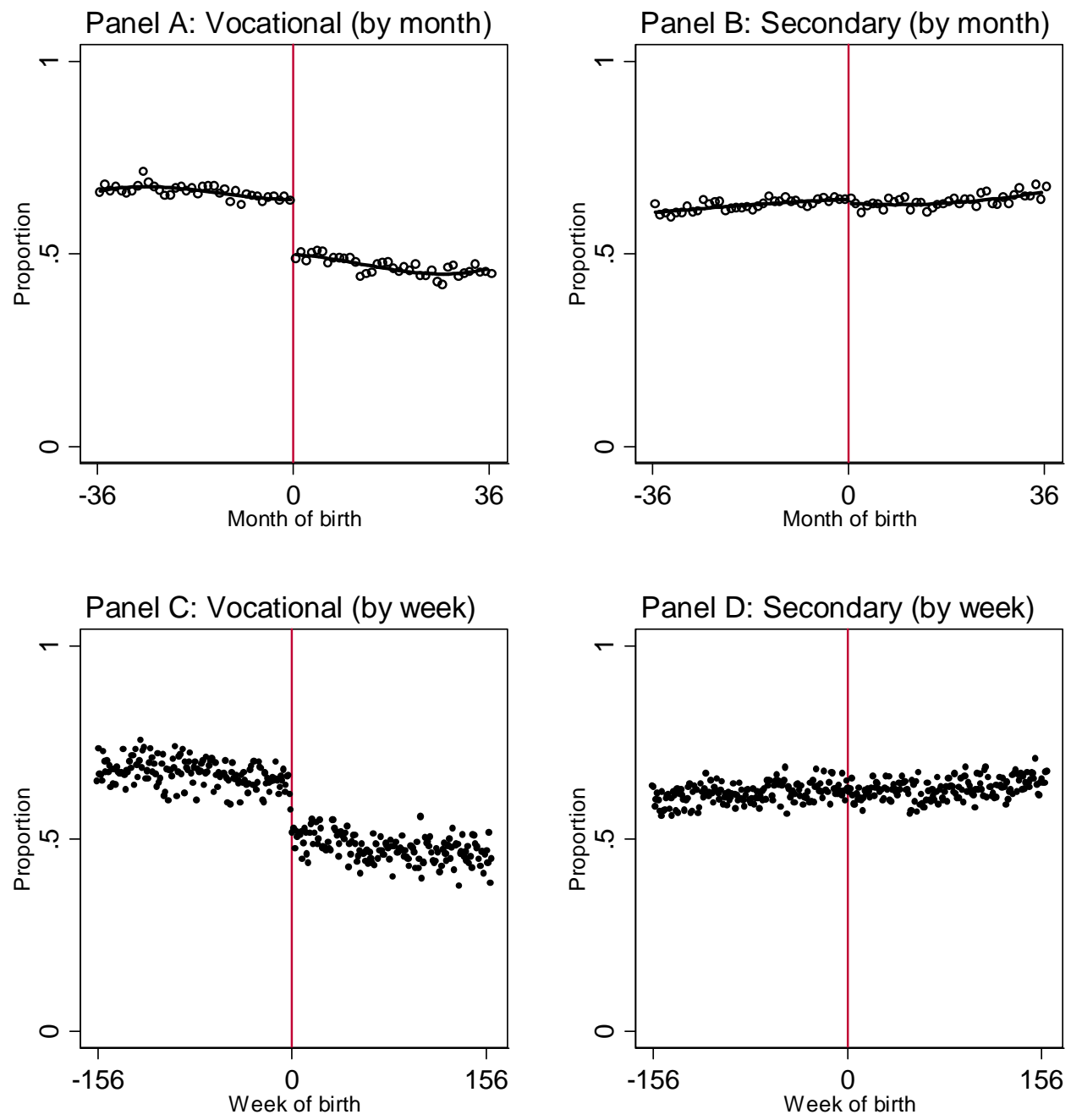

Notes: All panels are restricted to men born between January 1, 1956 and December 31, 1961. Panels A and C are further restricted to men whose highest educational attainment is at the secondary level (vocational or lyceum). The solid lines in Panels A and B are fitted values from regressions of the dependent variable on a cubic spline in month of birth. The open circles indicate the fraction of men employed in these occupations by month of birth (Panels A and B) or week of birth (Panels C and D). Source: 1992 Romanian Census (PAU sample). 
Figure 4: Labor Market Outcomes in 1992 (by month of birth)
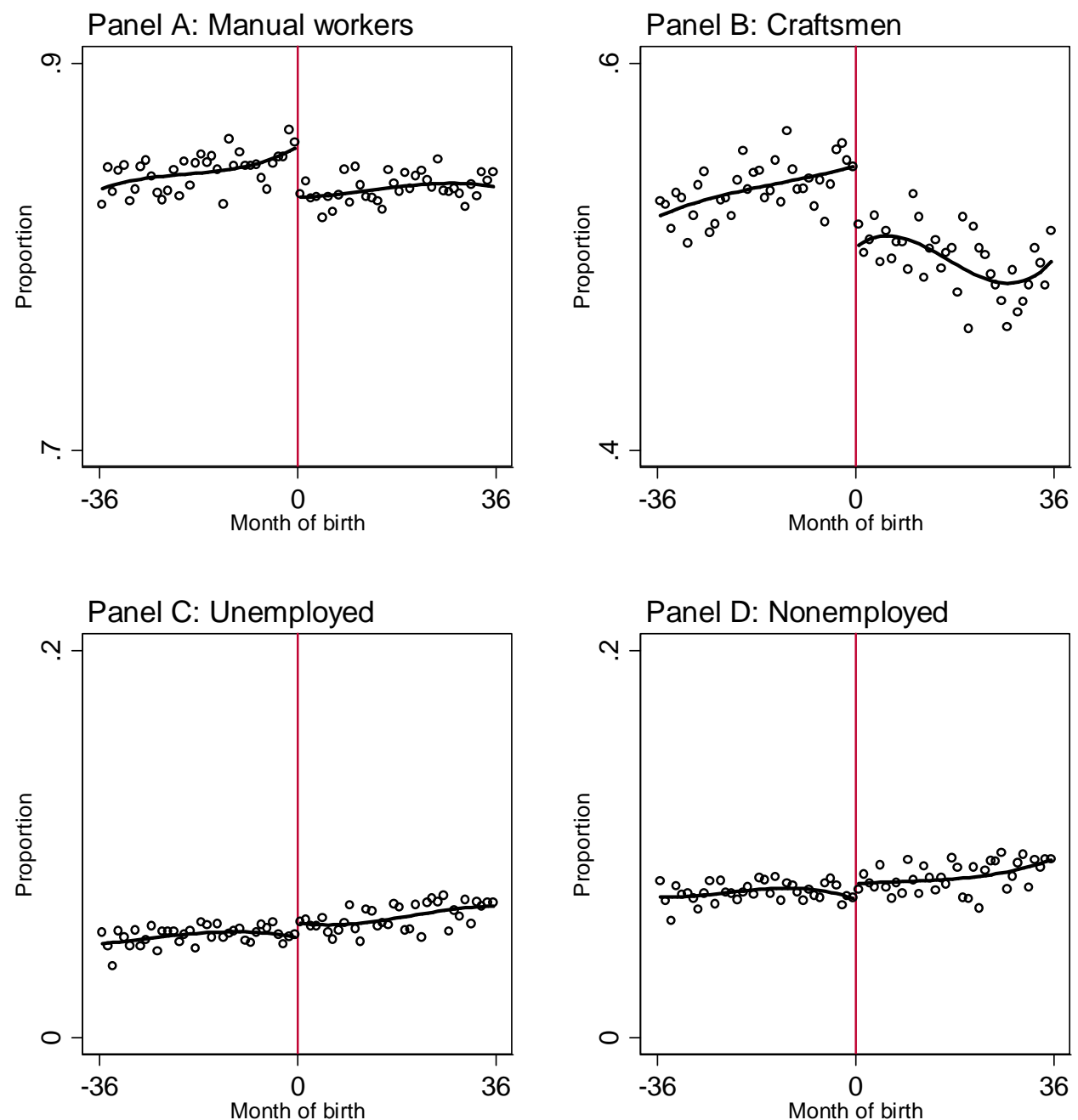

Notes: All panels are restricted to men with secondary education (vocational or lyceum) between January 1, 1956 and December 31, 1961. The solid lines are fitted values from regressions of the dependent variable on a cubic spline in month of birth. The open circles indicate the fraction of men employed in these occupations by month of birth. Source: 1992 Romanian Census. 
Figure 5: Labor Market Outcomes in 2002 (by month of birth)
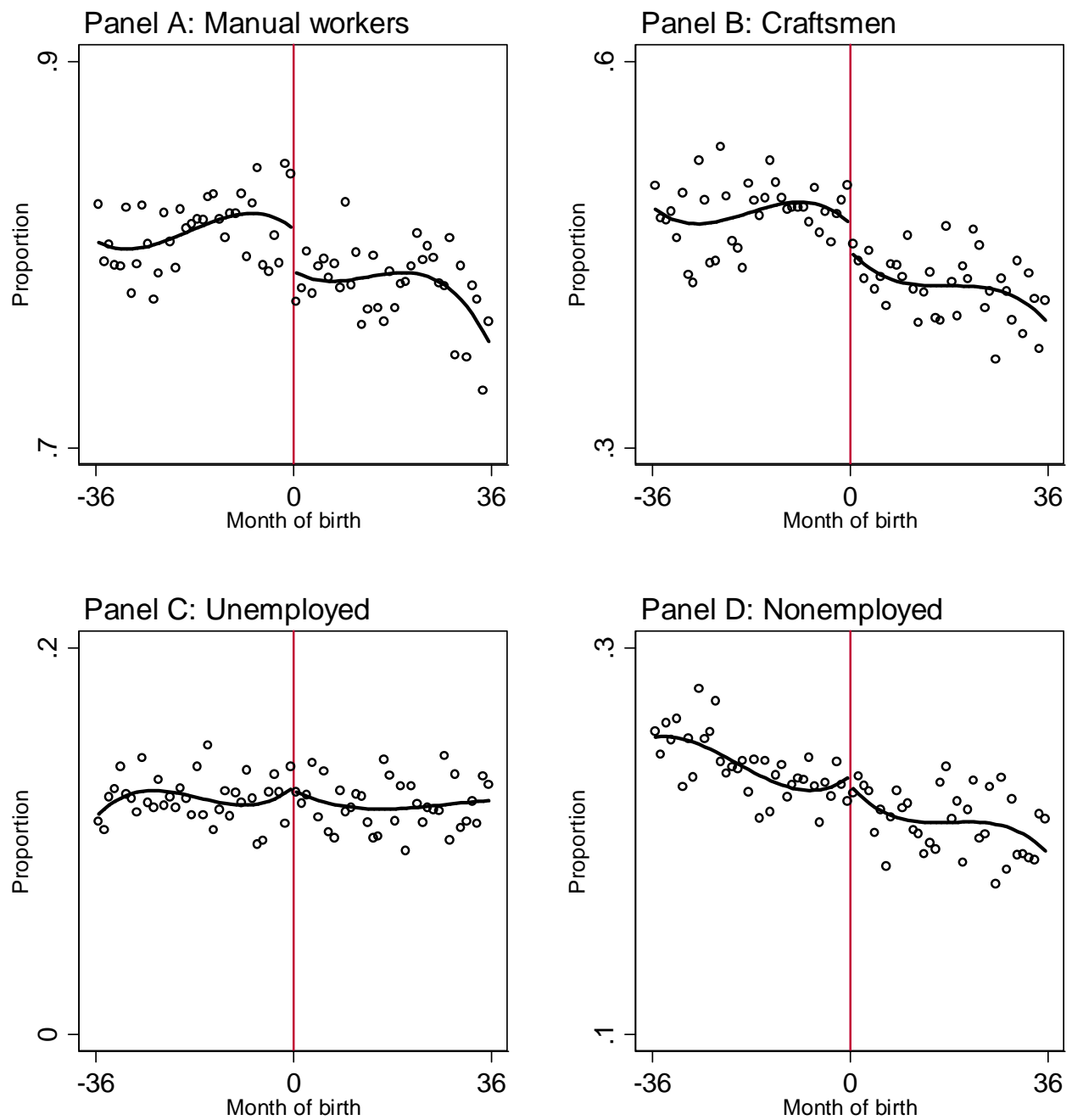

Notes: All panels are restricted to men with secondary education (vocational or lyceum) between January 1, 1956 and December 31, 1961. The solid lines are fitted values from regressions of the dependent variable on a cubic spline in month of birth. The open circles indicate the fraction of men employed in these occupations by month of birth. Source: 2002 Romanian Census. 
Figure 6: Labor Market Outcomes in 1995-2000 (by month of birth)
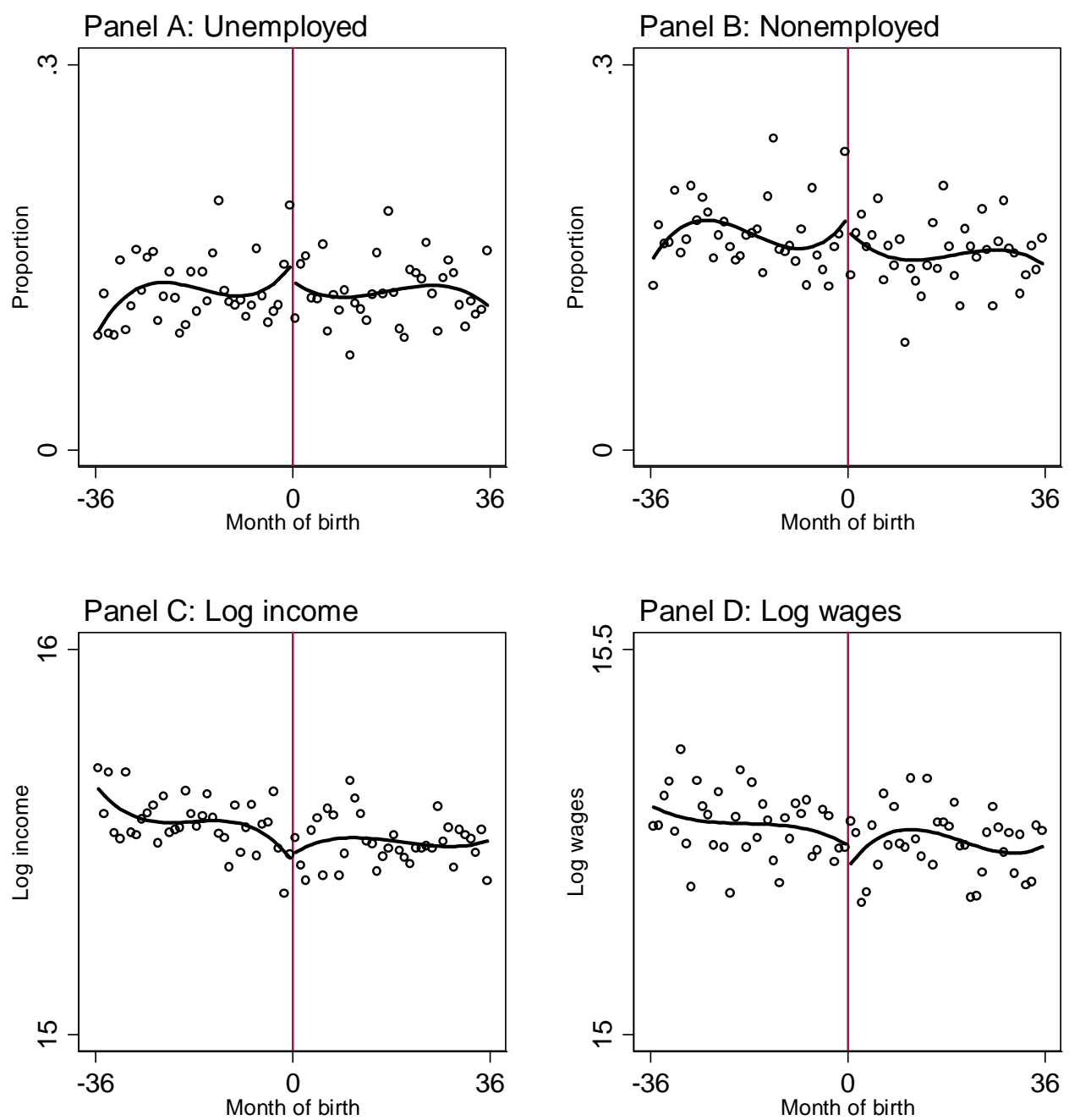

Notes: All panels are restricted to men with secondary education (vocational or lyceum) between January 1, 1956 and December 31, 1961. The solid lines are fitted values from regressions of the dependent variable on a cubic spline in month of birth. The open circles indicate the fraction of men that are unemployed and nonemployed, or the average log income and wages by month of birth. Source: LSMS 1995-2000. 
Appendix Figure 1: Enrollment in vocational schools and apprenticeships by school-year

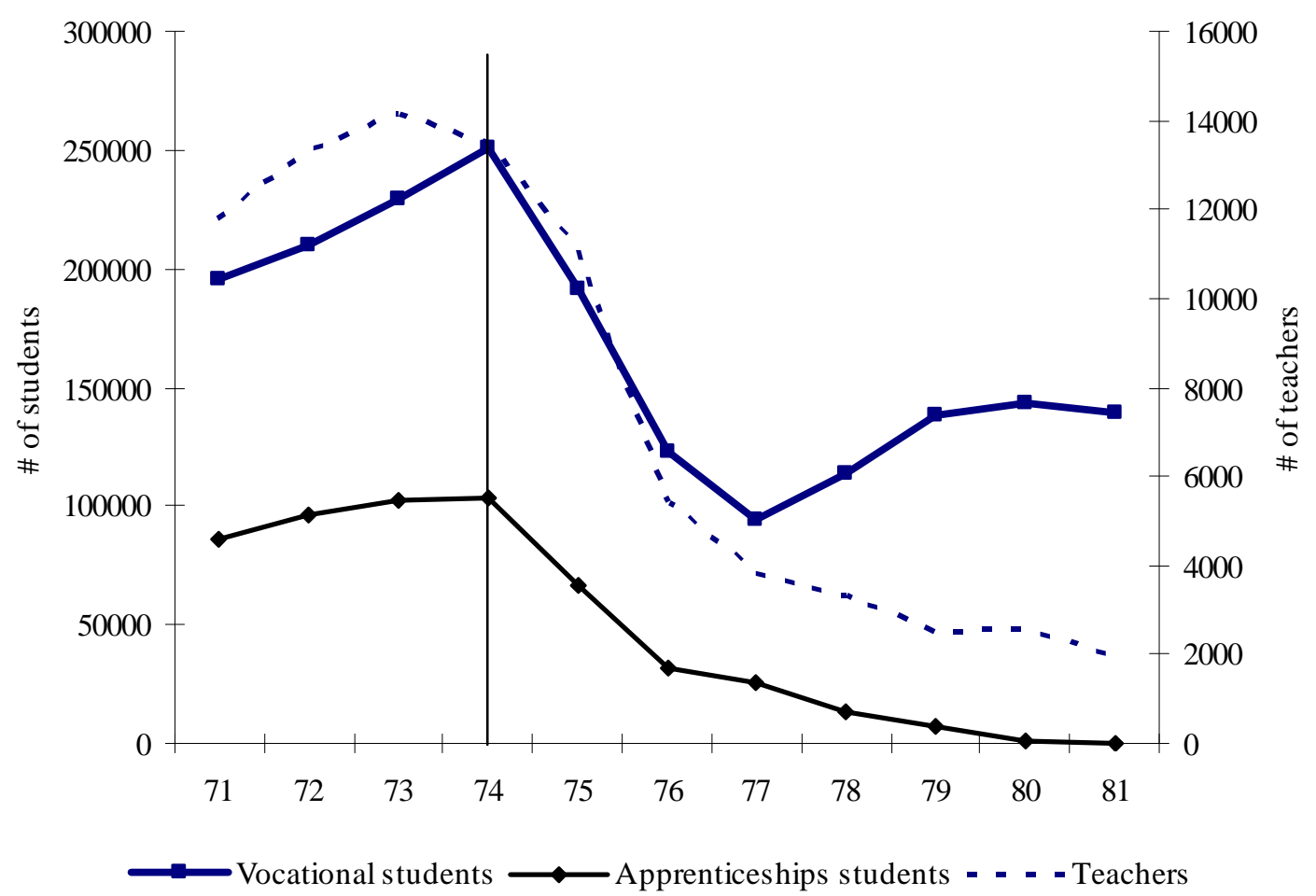

Appendix Figure 2: Enrollment in lyceums by school-year

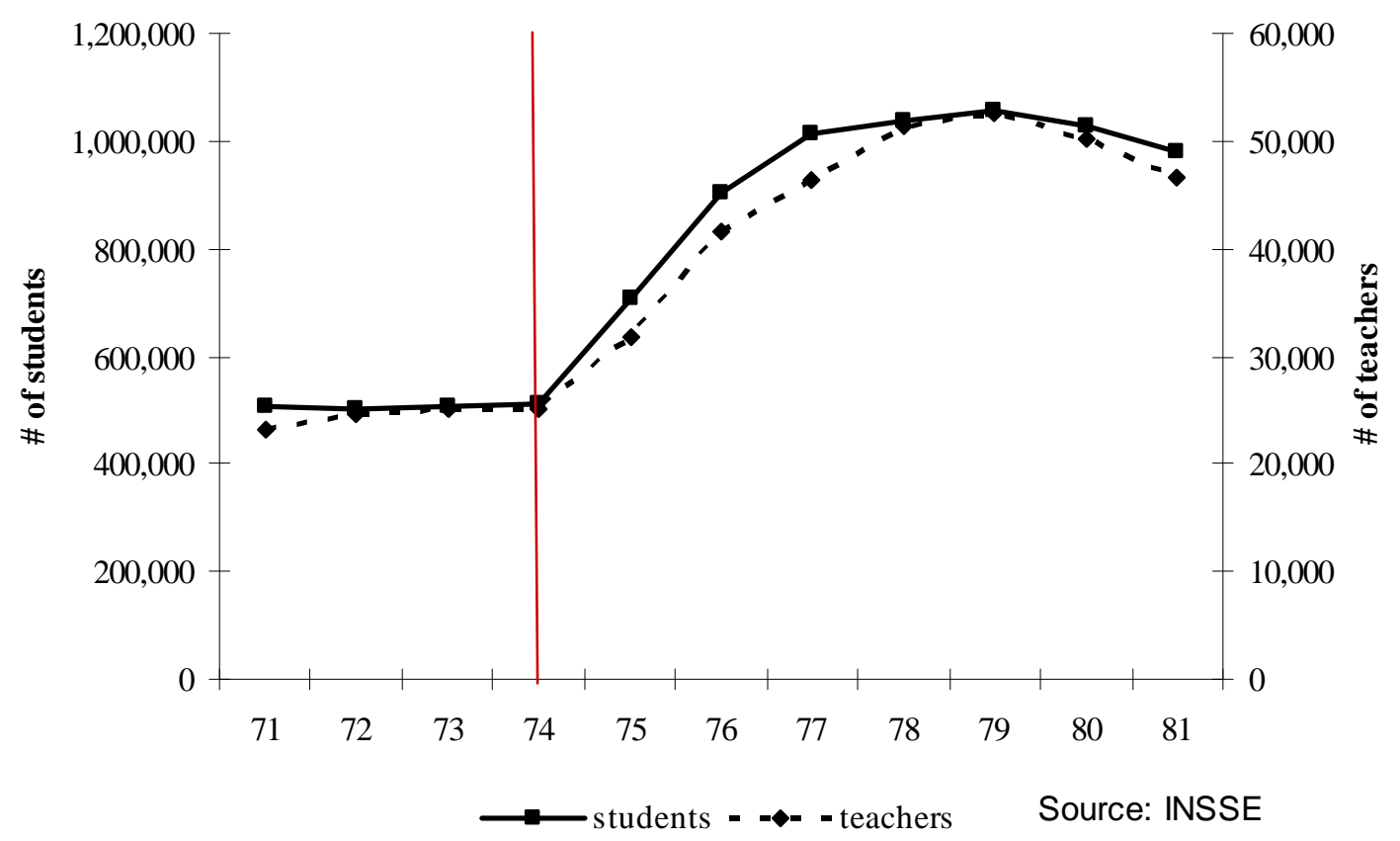


Appendix Figure 3: Recipients of Unemployment Benefits and Unemployment Rate in Romania (1991-2003)

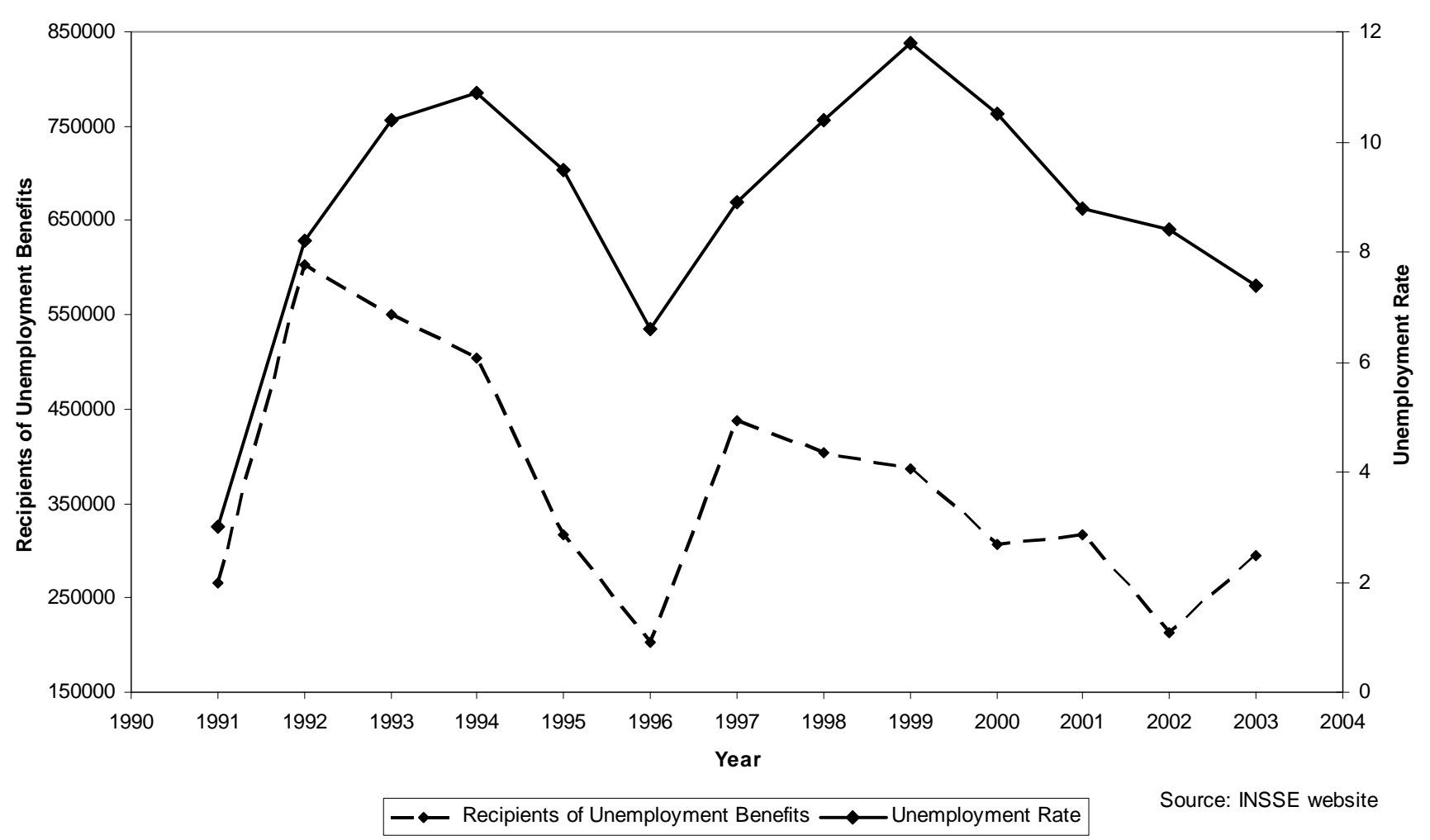

